\title{
Hygroscopicity distribution concept for measurement data analysis and modeling of aerosol particle mixing state with regard to hygroscopic growth and CCN activation
}

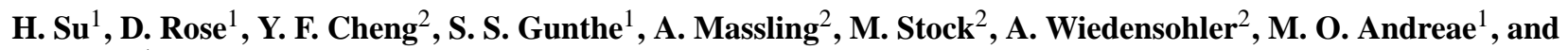 \\ U. Pöschl ${ }^{1}$ \\ ${ }^{1}$ Max Planck Institute for Chemistry, 55020 Mainz, Germany \\ ${ }^{2}$ Leibniz Institute for Tropospheric Research, 04318 Leipzig, Germany
}

Received: 8 December 2009 - Published in Atmos. Chem. Phys. Discuss.: 18 January 2010

Revised: 3 August 2010 - Accepted: 5 August 2010 - Published: 12 August 2010

\begin{abstract}
This paper presents a general concept and mathematical framework of particle hygroscopicity distribution for the analysis and modeling of aerosol hygroscopic growth and cloud condensation nucleus $(\mathrm{CCN})$ activity. The cumulative distribution function of particle hygroscopicity, $H\left(\kappa, D_{\mathrm{d}}\right)$ is defined as the number fraction of particles with a given dry diameter, $D_{\mathrm{d}}$, and with an effective hygroscopicity parameter smaller than the parameter $\kappa$. From hygroscopicity tandem differential mobility analyzer (HTDMA) and size-resolved CCN measurement data, $H\left(\kappa, D_{\mathrm{d}}\right)$ can be derived by solving the $\kappa$-Köhler model equation. Alternatively, $H\left(\kappa, D_{\mathrm{d}}\right)$ can be predicted from measurement or model data resolving the chemical composition of single particles.

A range of model scenarios are used to explain and illustrate the concept, and exemplary practical applications are shown with HTDMA and CCN measurement data from polluted megacity and pristine rainforest air. Lognormal distribution functions are found to be suitable for approximately describing the hygroscopicity distributions of the investigated atmospheric aerosol samples.

For detailed characterization of aerosol hygroscopicity distributions, including externally mixed particles of low hygroscopicity such as freshly emitted soot, we suggest that size-resolved $\mathrm{CCN}$ measurements with a wide range and high resolution of water vapor supersaturation and dry particle diameter should be combined with comprehensive HTDMA measurements and size-resolved or single-particle measure-
\end{abstract}

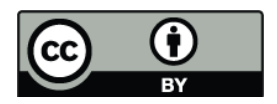

Correspondence to: $\mathrm{H}$. Su

(h.su@mpic.de) ments of aerosol chemical composition, including refractory components. In field and laboratory experiments, hygroscopicity distribution data from HTDMA and CCN measurements can complement mixing state information from optical, chemical and volatility-based techniques. Moreover, we propose and intend to use hygroscopicity distribution functions in model studies investigating the influence of aerosol mixing state on the formation of cloud droplets.

\section{Introduction}

Aerosol particles serving as cloud condensation nuclei (CCN) play an important role in the cloud formation process (Pruppacher and Klett, 1997). At a given water vapor supersaturation, the activation of CCN into cloud droplets is determined by particle size and composition, according to Köhler theory (Köhler, 1936). Petters and Kreidenweis (2007) proposed a $\kappa$-Köhler model approach using a simple parameter, $\kappa$, as a quantitative measure of aerosol water uptake characteristics and $\mathrm{CCN}$ activity. The values of $\kappa$ can be determined experimentally from hygroscopicity tandem differential mobility analyzer (HTDMA) and CCN measurement data.

Size dependence of $\kappa$ has been found in $\mathrm{CCN}$ measurements of atmospheric aerosols (Gunthe et al., 2009; Petters et al., 2009a; Rose et al., 2010a). The spread of $\kappa$ values among particles of the same size may be relevant for CCN activation and cloud formation but is not always described and used in earlier studies. Internally mixed particles have the same chemical composition and hence the same hygroscopicity, so differences in $\kappa$ among particles of the same

Published by Copernicus Publications on behalf of the European Geosciences Union. 
size indicate how well they are mixed. If the $\kappa$ distribution among particles of a given size can be measured, the (hygroscopicity related) particle mixing state can also be derived.

Thus, $\kappa$ distribution data can complement information about aerosol mixing state obtained with other measurement techniques like the volatility tandem differential mobility analyzer (VTDMA) (Orsini et al., 1996), the single-particle soot photometer (SP2) (Schwarz et al., 2006), scanning and transmission electron microscopes (STEM) and single particle mass spectrometers (SPMS) (McMurry et al., 1996; Buzorius et al., 2002; Krejci et al., 2005; Murphy et al., 2006).

In this paper, we introduce a concept of particle hygroscopicity distribution and we show how it can be related to hygroscopicity measurements. Model aerosols are used to explain and illustrate the concept. Exemplary applications are shown with HTDMA and CCN field measurement data from polluted megacity and pristine rainforest air. Early and recent HTDMA studies have already presented distributions of diameter growth factors, which are also related to particle hygroscopicity, and addressed the relation to aerosol mixing state (Stolzenburg and McMurry, 1988; Swietlicki et al., 2008; Kammermann et al., 2010). To our knowledge, however, a comprehensive concept of hygroscopicity distribution, including a general set of equations and a link to the measurement and prediction of $\mathrm{CCN}$ has not been presented before.

\section{Concept and methods}

\subsection{Hygroscopicity distribution}

\subsubsection{Definition}

Particle size distributions are widely used in aerosol science and atmospheric research (Seinfeld and Pandis, 2006). We introduce a similar concept and mathematical formalism for the hygroscopicity of aerosol particles, i.e., their ability to absorb water vapor. In an ensemble of aerosol particles, the hygroscopicity of each particle can be described by an "effective" hygroscopicity parameter $\kappa$ (Petters and Kreidenweis, 2007; Sullivan et al., 2009). Here "effective" means that the parameter accounts not only for the reduction of water activity by the solute but also for surface tension effects (Rose et al., 2008; Gunthe et al., 2009; Pöschl et al., 2009). For atmospheric aerosols, the range of $\kappa$ typically varies from as low as $\sim 0.01$ for some combustion aerosol particles up to $\sim 1$ for sea-salt particles (Petters and Kreidenweis, 2007; Andreae and Rosenfeld, 2008; Niedermeier et al., 2008; Petters et al., 2009a). When we assort the particles by $\kappa$, a hygroscopicity distribution can be defined and described in analogy to the size distribution of the aerosol population.
For particles with a dry diameter of $D_{\mathrm{d}}$, i.e., within an infinitesimal size range of $D_{\mathrm{d}}$ to $D_{\mathrm{d}}+d D_{\mathrm{d}}$, the fractional cumulative distribution function (CDF) of hygroscopicity, $H\left(\kappa, D_{\mathrm{d}}\right)$ is defined as the number fraction of particles having a hygroscopicity parameter smaller than $\kappa$. In other words, $H\left(\kappa, D_{\mathrm{d}}\right)$ is the number concentration of particles having a hygroscopicity parameter smaller than $\kappa$ divided by the total number concentration of particles in the size range $\left[D_{\mathrm{d}}, D_{\mathrm{d}}+d D_{\mathrm{d}}\right]$.

For every given diameter or size range, $H\left(\kappa, D_{\mathrm{d}}\right)$ is a normalized dimensionless CDF with a maximum value of one, i.e., $H\left(\kappa \rightarrow \infty, D_{\mathrm{d}}\right)=1$.

Accordingly, the fractional probability distribution function (PDF) of hygroscopicity, $h\left(\kappa, D_{\mathrm{d}}\right)$, is defined as the partial derivative of the $\mathrm{CDF}$ with respect to $\kappa$ :

$h\left(\kappa, D_{\mathrm{d}}\right)=\frac{\partial H\left(\kappa, D_{\mathrm{d}}\right)}{\partial \kappa}$

Note that $h\left(\kappa, D_{\mathrm{d}}\right)$ is also normalized and dimensionless but not limited to values $\leq 1$. Logarithmic PDFs are particularly useful for describing lognormally distributed ambient aerosols as detailed below. They can be defined and converted by the following equations:

$h_{e}\left(\kappa, D_{\mathrm{d}}\right)=\frac{\partial H\left(\kappa, D_{\mathrm{d}}\right)}{\partial \ln \kappa}$
$h_{10}\left(\kappa, D_{\mathrm{d}}\right)=\frac{\partial H\left(\kappa, D_{\mathrm{d}}\right)}{\partial \log \kappa}$
$h_{e}\left(\kappa, D_{\mathrm{d}}\right)=\kappa h\left(\kappa, D_{\mathrm{d}}\right)$
$h_{10}\left(\kappa, D_{\mathrm{d}}\right)=2.303 \kappa h\left(\kappa, D_{\mathrm{d}}\right)$

The hygroscopicity distribution concept is not limited to the effective hygroscopicity parameter $\kappa$ as outlined above. Similar distribution functions can also be defined and applied with other hygroscopicity parameters such as equivalent ion densities (Rissler et al., 2006; Wex et al., 2007) or equivalent soluble fractions of ammonium sulfate or bisulfate as used in many earlier studies (Gunthe et al., 2009 and references therein). Moreover, similar formalisms could also be based on the van't Hoff factor (McDonald, 1953) or the product of the stoichiometric dissociation number and osmotic coefficient of the solute (Robinson and Stokes, 1959; Rose et al., 2008; and references therein) averaged over all chemical components of a particle according to mixing rules (e.g., the Zdanovski-Stokes-Robinson approximation), or more advanced models taking into account complex solute interactions and concentration dependencies (e.g., the extended aerosol inorganic model of Clegg et al., 2008).

\subsubsection{Characteristic distribution parameters}

In many cases, it is convenient and useful to summarize the key features of distributions by a few parameters such as mean values and standard deviations. 
For particles with a dry diameter $D_{\mathrm{d}}$, the arithmetic mean $\left(\bar{\kappa}\left(D_{\mathrm{d}}\right)\right)$ and standard deviation $\left(\sigma_{\kappa}\left(D_{\mathrm{d}}\right)\right)$ of $\kappa$ are given by:

$\bar{\kappa}\left(D_{\mathrm{d}}\right)=\int_{0}^{\infty} \kappa h\left(\kappa, D_{\mathrm{d}}\right) d \kappa$

$\sigma_{\kappa}^{2}\left(D_{\mathrm{d}}\right)=\int_{0}^{\infty}\left(\kappa-\bar{\kappa}\left(D_{\mathrm{d}}\right)\right)^{2} h\left(\kappa, D_{\mathrm{d}}\right) d \kappa$

The geometric mean $\left(\bar{\kappa}_{\mathrm{g}}\left(D_{\mathrm{d}}\right)\right)$ and the geometric standard deviation $\left(\sigma_{\kappa, \mathrm{g}}\left(D_{\mathrm{d}}\right)\right)$ of $\kappa$ for particles with a dry diameter $D_{\mathrm{d}}$ are given by:

$\bar{\kappa}_{\mathrm{g}}\left(D_{\mathrm{d}}\right)=\exp \left(\int_{0}^{\infty}(\ln \kappa) h\left(\kappa, D_{\mathrm{d}}\right) d \kappa\right)$

$\ln ^{2} \sigma_{\kappa, \mathrm{g}}\left(D_{\mathrm{d}}\right)=\int_{0}^{\infty}\left(\ln \kappa-\ln \bar{\kappa}_{\mathrm{g}}\left(D_{\mathrm{d}}\right)\right)^{2} h\left(\kappa, D_{\mathrm{d}}\right) d \kappa$

The median $\left(\kappa_{\text {med }}\left(D_{\mathrm{d}}\right)\right)$ of $\kappa$ for particles with a dry diameter $D_{\mathrm{d}}$ is defined by:

$$
\begin{gathered}
H\left(\kappa_{\text {med }}\left(D_{\mathrm{d}}\right), D_{\mathrm{d}}\right)=0.5 \\
\int_{0}^{\kappa_{\text {med }}\left(D_{\mathrm{d}}\right)} h\left(\kappa, D_{\mathrm{d}}\right) d \kappa=0.5
\end{gathered}
$$

Modal values of the hygroscopicity distribution $\left(\kappa_{\text {mode }}\left(D_{\mathrm{d}}\right)\right)$, i.e., local maxima in a plot of $h\left(\kappa, D_{\mathrm{d}}\right)$ vs. $\kappa$, are defined by

$$
\left(\frac{\partial h\left(\kappa, D_{\mathrm{d}}\right)}{\partial \kappa}\right)_{\kappa_{\text {mode }}}=0
$$

By integration over all particle diameters, characteristic parameters can also be calculated for the entire particle population of an aerosol. For example, the total arithmetic mean value $\left(\bar{\kappa}_{\text {tot }}\right)$ and the total geometric mean value $\left(\bar{\kappa}_{\mathrm{g}, \text { tot }}\right)$ are given by:

$$
\bar{\kappa}_{\mathrm{tot}}=\frac{\int_{0}^{\infty} \bar{\kappa}\left(D_{\mathrm{d}}\right) n\left(D_{\mathrm{d}}\right) d D_{\mathrm{d}}}{\int_{0}^{\infty} n\left(D_{\mathrm{d}}\right) d D_{\mathrm{d}}}
$$

$\bar{\kappa}_{\mathrm{g}, \text { tot }}=\exp \left(\frac{\int_{0}^{\infty} \ln \left(\bar{\kappa}_{\mathrm{g}}\left(D_{\mathrm{d}}\right)\right) n\left(D_{\mathrm{d}}\right) d D_{\mathrm{d}}}{\int_{0}^{\infty} n\left(D_{\mathrm{d}}\right) d D_{\mathrm{d}}}\right)$

Here, $n\left(D_{\mathrm{d}}\right)$ is the particle number size distribution function (PDF), and $N\left(D_{\mathrm{d}}\right)$ is the number concentration of particles with a diameter smaller than $D_{\mathrm{d}}(\mathrm{CDF})$ :

$n\left(D_{\mathrm{d}}\right)=\frac{d N\left(D_{\mathrm{d}}\right)}{d D_{\mathrm{d}}}$

\subsubsection{Lognormal hygroscopicity distributions}

Aerosol hygroscopicity parameters determined from HTDMA and CCN measurements are often presented in discrete forms (tables or graphs). For efficient comparison, generalization, and use in theoretical studies, it is convenient to use standardized mathematical functions with a few variable parameters to fit and represent measurement data.

Aerosol particle size distributions are often described by one or multiple lognormal distribution functions (Aitchison and Brown, 1957; Seinfeld and Pandis, 2006). Accordingly, we suggest using cumulative lognormal distribution functions to describe $H\left(\kappa, D_{\mathrm{d}}\right)$ for given values of $D_{\mathrm{d}}$. Potential size dependencies of the characteristic CDF parameters can then be handled as detailed and illustrated below (Sects. 3 and 4).

The following expression of a multi-mode lognormal CDF can be used to fit $H\left(\kappa, D_{\mathrm{d}}\right)$ at a given value of $D_{\mathrm{d}}$ :

$H\left(\kappa, D_{\mathrm{d}}\right)=\sum_{i=1}^{m} a_{i}\left(D_{\mathrm{d}}\right)\left(\frac{1}{2}+\frac{1}{2} \operatorname{erf}\left(\frac{\log \kappa-\log \bar{\kappa}_{\mathrm{g}, i}\left(D_{\mathrm{d}}\right)}{\sqrt{2} \log \sigma_{\kappa, \mathrm{g}, i}\left(D_{\mathrm{d}}\right)}\right)\right)$

Here, "erf" is the Gauss error function, $m$ is the number of modes, and $a_{i}\left(D_{\mathrm{d}}\right), \bar{\kappa}_{\mathrm{g}, i}\left(D_{\mathrm{d}}\right)$ and $\sigma_{\kappa, \mathrm{g}, i}\left(D_{\mathrm{d}}\right)$ are the fit parameters for each mode ( $i=1$ to $m): a_{i}\left(D_{\mathrm{d}}\right)$ is the number fraction of mode $i, \bar{\kappa}_{\mathrm{g}, i}\left(D_{\mathrm{d}}\right)$ is the geometric mean or median value of $\kappa$ in mode $i$, and $\sigma_{\kappa, \mathrm{g}, i}\left(D_{\mathrm{d}}\right)$ is the geometric standard deviation of $\kappa$ in mode $i$.

\subsection{HTDMA data analysis}

In HTDMA measurements, nearly mono-disperse dry aerosol particles with a diameter $D_{\mathrm{d}}$ are selected by the first differential mobility analyzer (DMA) and subsequently equilibrated at a defined relative humidity, $\mathrm{RH}$, or water vapor saturation ratio, $s$, respectively $(s=\mathrm{RH} /(100 \%))$. Then a second DMA is used to measure the size distribution of the equilibrated wet particles. Integration of the wet particle size distribution, yields the number fraction of particles with wet diameters smaller than $D_{\mathrm{w}}$, which we denote as $F\left(D_{\mathrm{w}}, D_{\mathrm{d}}, s\right)$. For experimental uncertainties see Sect. 2.4.

According to the $\kappa$-Köhler approach (Petters and Kreidenweis, 2007), the equilibrium wet particle diameter, $D_{\mathrm{w}}$, depends on particle hygroscopicity $(\kappa)$ and water vapor saturation ratio $(s)$ :

$s=\frac{D_{\mathrm{w}}^{3}-D_{\mathrm{d}}^{3}}{D_{\mathrm{w}}^{3}-D_{\mathrm{d}}^{3}(1-\kappa)} \exp \left(\frac{4 \sigma_{\mathrm{sol}} M_{\mathrm{w}}}{R T \rho_{\mathrm{w}} D_{\mathrm{w}}}\right)$

Here, $\sigma_{\text {sol }}$ is the surface tension of a solution droplet (wet particle), $M_{\mathrm{w}}$ is the molar mass of water, $R$ is the universal gas constant, $T$ is the temperature, and $\rho_{\mathrm{w}}$ is the density of pure water. 
Assuming that $\sigma_{\text {sol }}$ equals the surface tension of water $\left(\sigma_{\mathrm{w}}=0.072 \mathrm{~J} \mathrm{~m}^{-2}\right.$ at $\left.298.15 \mathrm{~K}\right)$, an effective hygroscopicity parameter $\kappa$ can be calculated from $D_{\mathrm{w}}, D_{\mathrm{d}}$ and $s$ :

$\kappa\left(D_{\mathrm{w}}, D_{\mathrm{d}}, s\right)=1-\frac{D_{\mathrm{w}}^{3}}{D_{\mathrm{d}}^{3}}+\frac{D_{\mathrm{w}}^{3}-D_{\mathrm{d}}^{3}}{s D_{\mathrm{d}}^{3}} \exp \left(\frac{4 \sigma_{\mathrm{w}} M_{\mathrm{w}}}{R T \rho_{\mathrm{w}} D_{\mathrm{w}}}\right)$

Thus, the fraction of particles with a wet diameter smaller than $D_{\mathrm{w}}$ determined by HTDMA measurements corresponds to the fraction of particles with an effective hygroscopicity parameter smaller than $\kappa\left(D_{\mathrm{w}}, D_{\mathrm{d}}, s\right)$. Accordingly, every HTDMA data point of $F\left(D_{\mathrm{w}}, D_{\mathrm{d}}, s\right)$ directly corresponds to a data point of the cumulative hygroscopicity distribution:

$H\left(\kappa\left(D_{\mathrm{w}}, D_{\mathrm{d}}, s\right), D_{\mathrm{d}}\right)=F\left(D_{\mathrm{w}}, D_{\mathrm{d}}, s\right)$

Figure 1 shows an exemplary case of $H\left(\kappa, D_{\mathrm{d}}\right)$ derived from HTDMA measurements in Beijing, China (Massling et al., 2009). It is based on one-day average measurement results of 12 June 2004. The dry particle diameters selected by the first DMA were $80 \mathrm{~nm}$ and $150 \mathrm{~nm}$, respectively, and the RH range was $88.6 \% \pm 0.6 \%(s=0.886 \pm 0.006)$. The HTDMA calibration and data inversion accounted for the counting efficiency of the condensation particle counter (CPC) as well as for the transfer function of the DMA. Further details about the measurement campaign, techniques and conditions are given by Massling et al. (2009).

The curves in Fig. 1 indicate a bimodal hygroscopicity distribution for both $80 \mathrm{~nm}$ and $150 \mathrm{~nm}$ particles. The values of $H\left(\kappa, D_{\mathrm{d}}\right)$ at the lower end of the distribution curves are $\approx 0.2$, implying that $\approx 20 \%$ of the mono-disperse particles have $\kappa$ values $<0.01$. These particles are most likely externally mixed soot particles freshly emitted from strong local combustion sources, which are characteristic for polluted air in Chinese megacity regions (e.g., Garland et al., 2008, 2009; Cheng et al., 2009; Massling et al., 2009; Wehner et al., 2009; Rose et al., 2010a, b, c). The steep increase of $H\left(\kappa, D_{\mathrm{d}}\right)$ around $\kappa \sim 0.2$ indicates a lognormal mode in the hygroscopicity distribution (lognormal fits yield $R^{2}$ of 0.99 ), which can be tentatively explained by internally mixed particles consisting of varying amounts of sulfates, nitrates, organics and aged soot (Massling et al., 2009; Wiedensohler et al., 2009; Rose et al., 2010a, b, c).

Equation (18) has already been used in earlier studies (Petters and Kreidenweis, 2007; Petters et al., 2009b; Wex et al., $2009)$, and the derivation of $H\left(\kappa, D_{\mathrm{d}}\right)$ from HTDMA data will not be further discussed in this paper. Hygroscopicity distributions derived from HTDMA data can be further analyzed and plotted as illustrated below for $\mathrm{CCN}$ data (Sects. 3 and 4).

\subsection{CCN data analysis}

Cloud condensation nuclei $(\mathrm{CCN})$ are particles that can be activated to form cloud droplets at a given water vapor supersaturation $S$, which is usually reported in percent $(S=$

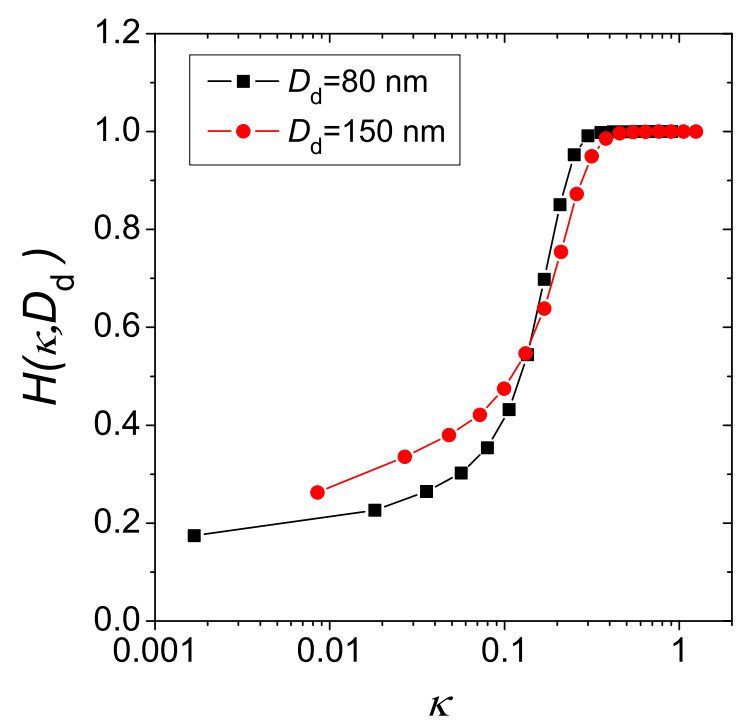

Fig. 1. Cumulative particle hygroscopicity distributions $H\left(\kappa, D_{\mathrm{d}}\right)$ calculated from exemplary HTDMA measurements performed in Beijing (one-day average for 12 June 2004). The dry particle diameters selected by the first DMA were $80 \mathrm{~nm}$ and $150 \mathrm{~nm}$, further details can be found in the work of Massling et al. (2009).

$(s-1) \cdot 100 \%)$. In field and laboratory studies, it is customary to measure the concentration of $\mathrm{CCN}$ with a cloud condensation nucleus counter (CCNC), while the total concentration of aerosol particles is measured with other types of condensation nucleus counters (CNC) or condensation particle counters (CPC), respectively. Thus, the index $\mathrm{CN}$ and the term $\mathrm{CN}$ concentration are often used for the total aerosol particle concentration, and we adopt this terminology in the present paper.

The cumulative size distribution functions of $\mathrm{CCN}$ and $\mathrm{CN}, N_{\mathrm{CCN}}\left(S, D_{\mathrm{d}}\right)$ and $N_{\mathrm{CN}}\left(D_{\mathrm{d}}\right)$, are defined as the number concentrations of CCN (at $S$ ) and CN smaller than $D_{\mathrm{d}}$, respectively (Sect. 2.1.2; Seinfeld and Pandis, 2006). Differentiation of $N_{\mathrm{CCN}}\left(S, D_{\mathrm{d}}\right)$ and $N_{\mathrm{CN}}\left(D_{\mathrm{d}}\right)$ for the dry particle diameter $D_{\mathrm{d}}$ yields the corresponding PDFs of the $\mathrm{CCN}$ and $\mathrm{CN}$ size distributions: $\partial N_{\mathrm{CCN}}\left(S, D_{\mathrm{d}}\right) / \partial D_{\mathrm{d}}$ and $d N_{\mathrm{CN}}\left(D_{\mathrm{d}}\right) / d D_{\mathrm{d}}$. Note that the PDF of the CN size distribution is a simple derivative because the corresponding $\mathrm{CDF}$ depends only on $D_{\mathrm{d}}$, whereas the PDF of the CCN size distribution is a partial derivative because the corresponding CDF depends on $D_{\mathrm{d}}$ and $S$. For every combination of $S$ and $D_{\mathrm{d}}$, the number ratio of $\mathrm{CCN} / \mathrm{CN}$ is given by the ratio of the corresponding size distribution functions:

$\frac{\partial N_{\mathrm{CCN}}\left(S, D_{\mathrm{d}}\right)}{\partial N_{\mathrm{CN}}\left(D_{\mathrm{d}}\right)}=\left(\frac{\partial N_{\mathrm{CCN}}\left(S, D_{\mathrm{d}}\right)}{\partial D_{\mathrm{d}}}\right) /\left(\frac{d N_{\mathrm{CN}}\left(D_{\mathrm{d}}\right)}{d D_{\mathrm{d}}}\right)$

Size-resolved CCN measurements can provide data of $\partial N_{\mathrm{CCN}}\left(S, D_{\mathrm{d}}\right) / \partial N_{\mathrm{CN}}\left(D_{\mathrm{d}}\right)$, or in practice $\Delta N_{\mathrm{CCN}}\left(S, D_{\mathrm{d}}\right) / \Delta N_{\mathrm{CN}}\left(D_{\mathrm{d}}\right)$ as a function of dry particle diameter and water vapor supersaturation. In such 
measurements, monodisperse dry aerosol particles with a diameter $D_{\mathrm{d}}$ are usually selected by a DMA, and the monodisperse aerosol is fed into a CCNC and into a CPC operated in parallel to measure the number concentrations of CCN $\left(\Delta N_{\mathrm{CCN}}\left(S, D_{\mathrm{d}}\right)\right)$ and of $\mathrm{CN}\left(\Delta N_{\mathrm{CN}}\left(D_{\mathrm{d}}\right)\right)$, respectively (e.g., Rose et al., 2008, 2010a). Note that different studies have used different terms for the quantity $\partial N_{\mathrm{CCN}}\left(S, D_{\mathrm{d}}\right) / \partial D_{\mathrm{d}}$, including the terms: activated particle fraction, CCN efficiency, or CCN efficiency ratio (e.g., Dusek et al., 2006; Frank et al., 2006; Kuwata et al., 2008; Rose et al., 2008, 2010a, b, c; Moore et al., 2009; Petters et al., 2009a; Wex et al., 2009; and references therein).

The size-resolved CCN efficiency $\partial N_{\mathrm{CCN}}\left(S, D_{\mathrm{d}}\right) /$ $\partial N_{\mathrm{CN}}\left(D_{\mathrm{d}}\right)$ is the number fraction of particles with a dry diameter $D_{\mathrm{d}}$ that are activated at a supersaturation $S$. According to the $\kappa$-Köhler theory, particles activated at a given combination of $S$ and $D_{\mathrm{d}}$ have effective hygroscopicity parameters that are equal or larger than a critical value $\kappa_{\mathrm{c}}$. Thus, $\partial N_{\mathrm{CCN}}\left(S, D_{\mathrm{d}}\right) / \partial N_{\mathrm{CN}}\left(D_{\mathrm{d}}\right)$ can be regarded as the fraction of particles with $\kappa \geq \kappa_{\mathrm{c}}$, which is complementary to the fractional CDF of particle hygroscopicity, $H\left(\kappa_{\mathrm{c}}\left(S, D_{\mathrm{d}}\right), D_{\mathrm{d}}\right)$ (fraction of particles with $\kappa<\kappa_{\mathrm{c}}$ ):

$H\left(\kappa_{\mathrm{c}}\left(S, D_{\mathrm{d}}\right), D_{\mathrm{d}}\right)=1-\frac{\partial N_{\mathrm{CCN}}\left(S, D_{\mathrm{d}}\right)}{\partial N_{\mathrm{CN}}\left(D_{\mathrm{d}}\right)}$

The critical hygroscopicity parameter value $\kappa_{\mathrm{c}}$ is a function of $S$ and $D_{\mathrm{d}}$. The general relation between $\kappa, S$, and $D_{\mathrm{d}}$ is given by Eq. (17) with $s=1+S /(100 \%)$, and for any given pair of parameter values the critical value of the third parameter can be determined by numerical calculation of the maximum point in the corresponding Köhler model curve of $\mathrm{CCN}$ activation (Rose et al., 2008). For example, $\kappa_{\mathrm{c}}$ can be determined by fixing $D_{\mathrm{d}}$ and varying both $\kappa$ and $D_{\mathrm{w}}$ until $S$ equals both the prescribed value and the maximum value in the Köhler curve. Alternatively, the critical parameter values $\kappa_{\mathrm{c}}, D_{\mathrm{d}, \mathrm{c}}$ and $S_{\mathrm{c}}$ can be approximated as follows (Petters and Kreidenweis, 2007, Rose et al., 2008):

$\kappa_{\mathrm{c}}\left(S, D_{\mathrm{d}}\right) \approx \frac{4 A^{3}}{27 D_{\mathrm{d}}^{3} \ln ^{2}(1+S /(100 \%))}$ with $A=\frac{\sigma_{\mathrm{sol}} M_{\mathrm{w}}}{R T \rho_{\mathrm{w}}}$
$\quad$ and $\sigma_{\mathrm{sol}}=\sigma_{\mathrm{w}}$

$D_{\mathrm{d}, \mathrm{c}}(\kappa, S) \approx \sqrt[3]{\frac{4 A^{3}}{27 \kappa \ln ^{2}(1+S /(100 \%))}}$

$S_{\mathrm{c}}\left(\kappa, D_{\mathrm{d}}\right) \approx\left(\exp \left(\sqrt{\frac{4 A^{3}}{27 \kappa D_{\mathrm{d}}^{3}}}\right)-1\right) 100 \%$

For CCN measurements at a fixed dry particle size $D_{\mathrm{d}}$, a given value of $S$ corresponds to a specific value of $\kappa_{\mathrm{c}}$ (Eq. 22), and every data point of $\partial N_{\mathrm{CCN}}\left(S, D_{\mathrm{d}}\right) / \partial N_{\mathrm{CN}}\left(D_{\mathrm{d}}\right)$ yields a value of $H\left(\kappa_{\mathrm{c}}, D_{\mathrm{d}}\right)$ (Eq. 21). To obtain the complete distribution function $H\left(\kappa, D_{\mathrm{d}}\right)$ for a given particle size $D_{\mathrm{d}}$, $S$ can be varied so that $\kappa_{\mathrm{c}}$ covers the whole relevant range of $\kappa$. By applying the same procedure for particles at other $D_{\mathrm{d}}$, a complete representation of $H\left(\kappa, D_{\mathrm{d}}\right)$ over the $D_{\mathrm{d}}-\kappa$ plane can be obtained. The approach of keeping $D_{\mathrm{d}}$ constant and varying $S$, then selecting another value of $D_{\mathrm{d}}$ and iterating the procedure, has been adopted in some size-resolved CCN measurement studies (e.g., Dusek et al., 2006; Frank et al., 2006; Moore et al., 2009; Snider et al., 2010) and will be called method I or " $S$ scan" in the following. Alternatively, $S$ can be kept constant while varying $D_{\mathrm{d}}$, before another value of $S$ is selected and the procedure is iterated (e.g., Kuwata et al., 2008; Rose et al., 2008, 2010a; Gunthe et al., 2009; Petters et al., 2009a; Wex et al., 2009), which will be called method II or " $D_{\mathrm{d}}$ scan".

Figure 2 illustrates the two different approaches that can be taken to determine $H\left(\kappa, D_{\mathrm{d}}\right)$ by size-resolved $\mathrm{CCN}$ measurements. Each line represents one measurement cycle. The vertical dashed lines correspond to method I " $S$ scan" at constant $D_{\mathrm{d}}$ ), and the tilted solid lines correspond to method II (" $D_{\mathrm{d}}$ scan" at constant $S$ ).

In principle, the two methods are equivalent with regard to probing the surface of $H\left(\kappa, D_{\mathrm{d}}\right)$ over the $D_{\mathrm{d}}-\kappa$ plane. In method I, each scan yields a complete hygroscopicity distribution of particles with the same dry diameter. In method II, the data points of a measurement scan give values of $H\left(\kappa, D_{\mathrm{d}}\right)$ for particles with different dry particle diameters. When we calculate the derivative of $H\left(\kappa, D_{\mathrm{d}}\right)$ with respect to $\kappa$ within each scan, method I gives a partial derivative $\partial H\left(\kappa, D_{\mathrm{d}}\right) / \partial \kappa$ while method II gives a total derivative $d H\left(\kappa, D_{\mathrm{d}}\right) / d \kappa$. The relation between the total derivative at constant $S$ and the partial derivative at constant $D_{\mathrm{d}}$ is given by:

$$
\frac{d H\left(\kappa, D_{\mathrm{d}}\right)}{d \kappa}=\frac{\partial H\left(\kappa, D_{\mathrm{d}}\right)}{\partial \kappa}+\frac{\partial H\left(\kappa, D_{\mathrm{d}}\right)}{\partial D_{\mathrm{d}}}\left(\frac{d D_{\mathrm{d}}}{d \kappa}\right)_{S}
$$

The term $\left(d D_{\mathrm{d}} / d \kappa\right)_{S}$ can be approximated by differentiating Eq. (23):

$$
\left(\frac{d D_{\mathrm{d}}}{d \kappa}\right)_{S}=-\frac{1}{3} \frac{D_{\mathrm{d}}}{\kappa}
$$

By combination of Eqs. (24) and (25), and multiplication with $\kappa$, we obtain

$$
\begin{aligned}
& \frac{d H\left(\kappa, D_{\mathrm{d}}\right)}{d \kappa}=\frac{\partial H\left(\kappa, D_{\mathrm{d}}\right)}{\partial \kappa}-\frac{1}{3} \frac{D_{\mathrm{d}}}{\kappa} \frac{\partial H\left(\kappa, D_{\mathrm{d}}\right)}{\partial D_{\mathrm{d}}} \\
& \quad \text { and } \\
& \frac{d H\left(\kappa, D_{\mathrm{d}}\right)}{d \ln \kappa}=\frac{\partial H\left(\kappa, D_{\mathrm{d}}\right)}{\partial \ln \kappa}-\frac{1}{3} \frac{\partial H\left(\kappa, D_{\mathrm{d}}\right)}{\partial \ln D_{\mathrm{d}}}
\end{aligned}
$$

or

$$
\frac{d H\left(\kappa, D_{\mathrm{d}}\right)}{d \log \kappa}=\frac{\partial H\left(\kappa, D_{\mathrm{d}}\right)}{\partial \log \kappa}-\frac{1}{3} \frac{\partial H\left(\kappa, D_{\mathrm{d}}\right)}{\partial \log D_{\mathrm{d}}}
$$




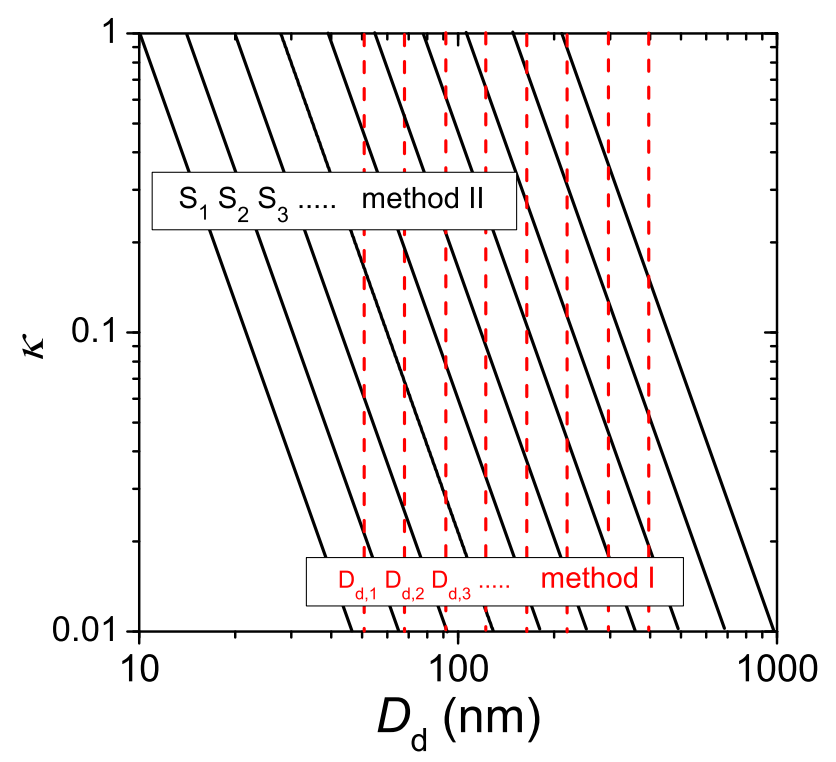

Fig. 2. Alternative methods of probing particle hygroscopicity distributions, $H\left(\kappa, D_{\mathrm{d}}\right)$, by size-resolved CCN measurements: (1) method I or " $S$ scan" is represented by vertical dashed lines, in which the dry particle diameter $D_{\mathrm{d}}$ is first kept constant and the water vapor supersaturation $S$ is varied, then choosing another $D_{\mathrm{d}}$ and repeating the same procedure; (2) method II or " $D_{\mathrm{d}}$ scan" is represented by the tilted solid lines, in which $S$ is first kept constant and $D_{\mathrm{d}}$ is varied, then choosing another $S$ and repeating the same procedure.

Recalling the definition of the PDFs of particle hygroscopicity, $h\left(\kappa, D_{\mathrm{d}}\right), h_{e}\left(\kappa, D_{\mathrm{d}}\right)$ and $h_{10}\left(\kappa, D_{\mathrm{d}}\right)$ (Eqs. 1 to 3$)$, we can rewrite Eqs. (27), (28) and (29) as follows:

$$
\begin{aligned}
& h\left(\kappa, D_{\mathrm{d}}\right)=\frac{d H\left(\kappa, D_{\mathrm{d}}\right)}{d \kappa}+\frac{1}{3} \frac{D_{\mathrm{d}}}{\kappa} \frac{\partial H\left(\kappa, D_{\mathrm{d}}\right)}{\partial D_{\mathrm{d}}} \\
& h_{e}\left(\kappa, D_{\mathrm{d}}\right)=\frac{d H\left(\kappa, D_{\mathrm{d}}\right)}{d \ln \kappa}+\frac{1}{3} \frac{\partial H\left(\kappa, D_{\mathrm{d}}\right)}{\partial \ln D_{\mathrm{d}}}
\end{aligned}
$$

and

$h_{10}\left(\kappa, D_{\mathrm{d}}\right)=\frac{d H\left(\kappa, D_{\mathrm{d}}\right)}{d \log \kappa}+\frac{1}{3} \frac{\partial H\left(\kappa, D_{\mathrm{d}}\right)}{\partial \log D_{\mathrm{d}}}$

As outlined above, method I with " $S$ scan" at constant $D_{\mathrm{d}}$ directly leads to $h\left(\kappa, D_{\mathrm{d}}\right)$ and $h_{e}\left(\kappa, D_{\mathrm{d}}\right)$ or $h_{10}\left(\kappa, D_{\mathrm{d}}\right)$, respectively. In contrast, the measurement results of method II (" $D_{\mathrm{d}}$ scan" at constant $S$ ) have to be combined with information about the size dependence of $H\left(\kappa, D_{\mathrm{d}}\right)$ to calculate the $h\left(\kappa, D_{\mathrm{d}}\right)$ s and characteristic hygroscopicity distribution parameters for a given particle size.

As indicated by Eq. (32) and discussed below (Sect. 4.1), $h_{10}\left(\kappa, D_{\mathrm{d}}\right)$ can be approximated by the total derivative $d H\left(\kappa, D_{d}\right) / d \log \kappa$ provided that $H\left(\kappa, D_{\mathrm{d}}\right)$ exhibits no strong size dependence, i.e., $\left|\partial H\left(\kappa, D_{\mathrm{d}}\right) / \partial \log D_{\mathrm{d}}\right| \ll$ $\left|\partial H\left(\kappa, D_{\mathrm{d}}\right) / \partial \log \kappa\right|$, which is likely to be the case under most atmospheric conditions.
Overall, the results of method I appear easier to interpret and compare directly with size-resolved data of aerosol chemical composition. Nevertheless the following discussions will be mostly focused on method II, because many of the recently reported size-resolved CCN field measurements used this approach (varying $D_{\mathrm{d}}$ at a constant $S$ ).

For completeness, we also give the equation which calculates the total CCN concentration at $S, N_{\mathrm{CCN}}\left(S, D_{\mathrm{d}} \rightarrow\right.$ $\infty)$, from the particle hygroscopicity and size distribution, $H\left(\kappa, D_{\mathrm{d}}\right)$ and $n\left(D_{\mathrm{d}}\right)$ :

$N_{\mathrm{CCN}}\left(S, D_{\mathrm{d}} \rightarrow \infty\right)=\int_{0}^{\infty} n\left(D_{\mathrm{d}}\right)\left(1-H\left(\kappa_{\mathrm{c}}\left(S, D_{\mathrm{d}}\right), D_{\mathrm{d}}\right)\right) d D_{\mathrm{d}}$

Note that Eq. (33) is equivalent to the approach of calculating CCN number concentrations in experimental studies applying method II (e.g. Gunthe et al., 2009; Rose et al., $2010 \mathrm{a})$, because the term $\left(1-H\left(\kappa_{\mathrm{c}}\left(S, D_{\mathrm{d}}\right), D_{\mathrm{d}}\right)\right)$ is the measured CCN efficiency spectra.

\subsection{Uncertainties and validation}

Uncertainties in the determination of $H\left(\kappa, D_{\mathrm{d}}\right)$ from HTDMA and CCN measurement data are directly related to experimental uncertainties in the determination of $F\left(D_{\mathrm{w}}, D_{\mathrm{d}}, s\right)$ and $\Delta N_{\mathrm{CCN}}\left(S, D_{\mathrm{d}}\right) / \Delta N_{\mathrm{CN}}\left(D_{\mathrm{d}}\right)$, respectively. The experimental uncertainties depend on various factors like instrument calibration, counting statistics, correction factors, and data inversion techniques (counting efficiency, electric charge, DMA transfer function, particle shape, etc.; Rissler et al., 2006; Rose et al., 2008; Swietlicki et al., 2008; Massling et al., 2009; Mikhailov et al., 2009; Kammermann et al., 2010; Snider et al., 2010).

As demonstrated by Rose et al. (2008), CCN measurements require careful calibration to achieve relative uncertainties $<10 \%$ for $S$, corresponding to relative uncertainties $<20 \%$ for $\kappa\left(\partial \ln \kappa_{\mathrm{c}} / \partial \ln S \approx-2\right.$, in analogy to the sensitivity given in Kreidenweis et al., 2009). Especially at low supersaturation $(S \leq 0.1 \%)$, inappropriate calibration techniques can lead to relative errors $>40 \%$ in $S$ and larger errors in $\kappa$.

Moreover, $\kappa$ values determined by HTDMA measurements can be different from $\kappa$ values determined by $\mathrm{CCN}$ measurements, because of the general dependence of $\kappa$ and equivalent hygroscopicity parameters (van't Hoff factor and osmotic coefficient) on solute concentrations (Mikhailov et al., 2004, 2009; Rose et al., 2008; Reutter et al., 2009) and potential solubility effects (Petters and Kreidenweis, 2007).

Thus, the uncertainty, applicability, and extrapolation of hygroscopicity distributions determined by HTDMA or CCN measurements depend on the ambient and experimental conditions and on the quality of the measurement data (e.g., Rissler et al., 2006; Svenningson et al., 2006; Vestin et al., 2007; Gunthe et al., 2009; Petters et al., 2009a; Wex et al., 2009). 
For comparison and validation, hygroscopicity distributions can be calculated as a function of relative humidity, if the chemical composition and mixing state of the particle population as well as the hygroscopic properties and interactions of the chemical components are known or can be estimated reasonably well. Simple mixing rules or advanced models can be used for such purposes, and the effects of concentration-dependent changes in water activity, surface tension or partial molar volumes can be resolved explicitly. Thus, accurate parallel measurements of aerosol chemical composition, mixing state and hygroscopicity distributions should enable mutual validation of experimental and model results (closure). A more detailed discussion of these aspects would go beyond the scope of the present manuscript, which is aimed at introducing and illustrating the general concept of aerosol hygroscopicity distribution, but it should be pursued in follow-up studies.

\section{CCN efficiency spectra calculated from model hygroscopicity distributions}

In this section, we show how different hygroscopicity distributions are reflected in the $\mathrm{CCN}$ efficiency spectra (activation curves) of size-resolved $\mathrm{CCN}$ measurements. We consider three hypothetical model scenarios with different aerosol mixing states and lognormal distribution functions $H\left(\kappa, D_{\mathrm{d}}\right)$ (Cases A-C, Table 1$)$ and calculate the corresponding activation curves for " $D_{\mathrm{d}}$ scan" at constant $S$ (method II). Different terms and attributes have been used to describe the mixing state of aerosols. Here we use the attribute "internally mixed" not only for an aerosol in which all particles have the exact same composition and properties (Case A, perfect internal mixing), but also for particles with a continuum of similar compositions and properties, i.e., for an aerosol with a single lognormal mode of $\kappa$ (Case B, imperfect internal mixing). The attribute "externally mixed" is used for pronouncedly different types of particles, e.g., for aerosols with two distinct lognormal modes of $\kappa$ (Case C, external mixing).

\subsection{Perfect internally mixed aerosol (Case A)}

In Case A, the aerosol was assumed to be perfectly well internally mixed, i.e., all particles have the same composition and hygroscopicity. This scenario corresponds to a monodisperse distribution $H\left(\kappa, D_{\mathrm{d}}\right)$ of the form $H\left(\kappa<0.2, D_{\mathrm{d}}\right)=$ 0 and $H\left(\kappa \geq 0.2, D_{\mathrm{d}}\right)=1$. Ideal CCN measurements with " $D_{\mathrm{d}}$ scan" at $S=0.86 \%, 0.26 \%$ and $0.067 \%$ would yield activation curves in the form of perfect step functions as shown in Fig. 3 (blue lines). All particles would be activated above and none would be activated below the critical dry diameter $\left(D_{\mathrm{d}, \mathrm{c}}\right)$, which is given by Eq. (23). Note that such step functions could be observed only under ideal conditions (perfect particle generation, measurement, and data analysis). In practice, the experimental uncertainties mentioned above
Table 1. Lognormal hygroscopicity distribution parameters for model aerosols (Cases A to C, Eq. 16)

\begin{tabular}{|c|c|c|c|c|c|c|}
\hline & \multicolumn{3}{|c|}{ Mode I } & \multicolumn{3}{|c|}{ Mode II } \\
\hline & $a_{1}$ & $\bar{\kappa}_{\mathrm{g}, 1}$ & $\sigma_{\kappa, \mathrm{g}, 1}$ & $a_{2}$ & $\bar{\kappa}_{\mathrm{g}, 2}$ & $\sigma_{\kappa, \mathrm{g}, 2}$ \\
\hline Case A & 1 & 0.2 & 1 & - & - & - \\
\hline Case B & 1 & 0.2 & 1.6 & - & - & - \\
\hline Case C & 0.8 & $0.2\left(D_{\mathrm{d}} / 20 \mathrm{~nm}\right)^{0.4}$ & 1.6 & 0.2 & 0.05 & 1.1 \\
\hline
\end{tabular}

(particle shape and charge effects, DMA transfer function, inhomogeneities of $T$ and $\mathrm{RH}$, etc.) will result in some dispersion even for pure calibration aerosols (Rose et al., 2008; Svenningsson et al., 2008; Mikhailov et al, 2009; Snider et al., 2010; and references therein).

\subsection{Imperfect internally mixed aerosol with a single $\kappa$ mode (Case B)}

In Case B, we assumed an aerosol with a non-size-dependent $\kappa$ distribution consisting of a single lognormal mode with $a\left(D_{\mathrm{d}}\right)=1, \bar{\kappa}_{\mathrm{g}}\left(D_{\mathrm{d}}\right)=0.2$ and $\sigma_{\kappa, \mathrm{g}}\left(D_{\mathrm{d}}\right)=1.6$ (Eq. 16, Table 1). The corresponding PDF of particle hygroscopicity, $h_{10}\left(\kappa, D_{\mathrm{d}}\right)$ is illustrated in Fig. 4a. Size-resolved CCN measurements with " $D_{\mathrm{d}}$ scan" at $S=0.86 \%, 0.26 \%$, and $0.067 \%$ (tilted black lines in Fig. 4a), would yield activation curves in the form of lognormal CDFs as shown in Fig. 3 (green curves).

\subsection{Externally mixed aerosols with two $\kappa$ modes (Case C)}

In Case $\mathrm{C}$, we assume an externally mixed aerosol with two lognormally distributed modes of $H\left(\kappa, D_{\mathrm{d}}\right)$ (Table 1$)$. For mode 1 , the values of $\bar{\kappa}_{\mathrm{g}, 1}$ was the same as in Case B at $D_{\mathrm{d}}=20 \mathrm{~nm}$, but with increasing particle diameter we prescribed an increase of the geometric mean value of $\kappa$ as $\bar{\kappa}_{\mathrm{g}, 1}\left(D_{\mathrm{d}}\right)=0.2\left(D_{\mathrm{d}} / 20 \mathrm{~nm}\right)^{0.4}$. The $\sigma_{\kappa, \mathrm{g}, 1}$ was set to 1.6 for all $D_{\mathrm{d}}$. For mode 2, we assumed non-size-dependent values of $\bar{\kappa}_{\mathrm{g}, 2}=0.05$ and $\sigma_{\kappa, \mathrm{g}, 2}=1.1$. The corresponding PDF of particle hygroscopicity, $h_{10}\left(\kappa, D_{\mathrm{d}}\right)$ is illustrated in Fig. 4b. Size-resolved CCN measurements with " $D_{\mathrm{d}}$ scan" at $S=0.86 \%, 0.26 \%$, and $0.067 \%$ (tilted black lines in Fig. $4 \mathrm{~b}$ ), would yield activation curves in the form of two-mode lognormal CDFs as shown in Fig. 3 (red curves). Similar CCN efficiency spectra have been recorded in polluted megacity air (Sect. 4.2, Rose et al., 2010a).

\section{Retrieval of hygroscopicity distributions from $\mathrm{CCN}$ efficiency spectra}

In this section, we show how CDFs and PDFs of particle hygroscopicity can be retrieved from CCN efficiency spectra 


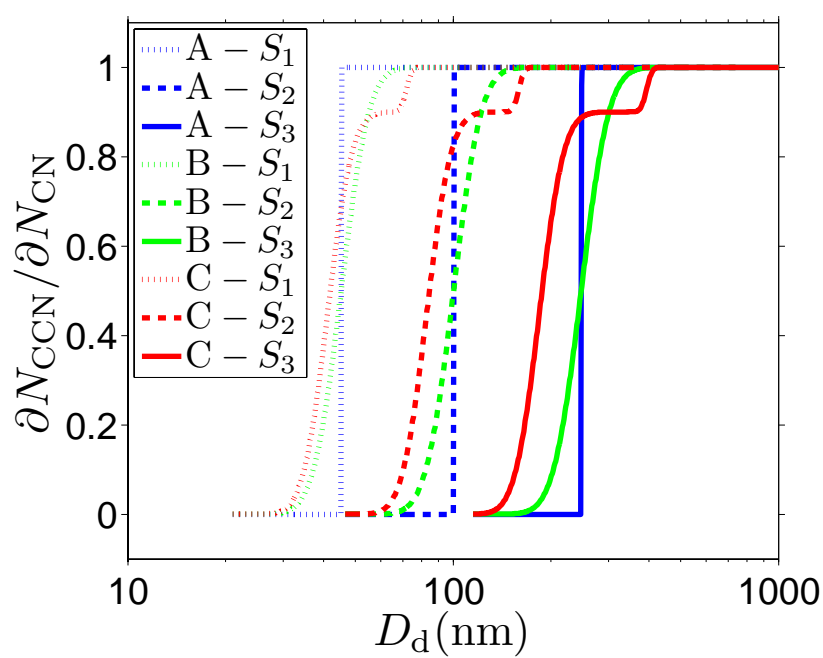

Fig. 3. CCN efficiency spectra (activation curves) of hypothetical model aerosols. Each line represents the spectrum of one type of mode aerosol (Case A, B, or C as specified in Table 1) obtained by $D_{\mathrm{d}}$ scans at a fixed supersaturation $S$. The supersaturation levels are $S_{1}=0.86 \%, S_{2}=0.26 \%$, or $S_{3}=0.067 \%$.

obtained by method II (" $D_{\mathrm{d}}$ scan" at constant $S$ ). We consider the three hypothetical model scenarios discussed above, as well as measurement data from recent field campaigns. Moreover, we address the difference between partial and total derivatives of the hygroscopicity distribution obtained by methods I and II, and we demonstrate the applicability of lognormal distribution functions for the fitting of measurement data.

\subsection{Modeled CCN efficiency spectra and differences between methods I and II}

To derive the cumulative hygroscopicity distribution $H\left(\kappa, D_{\mathrm{d}}\right)$ from a CCN efficiency spectrum observed at constant $S$ (activation curve of " $D_{\mathrm{d}}$ scan" in method II), Eqs. (20) and (21) can be used to convert every value of $\partial N_{\mathrm{CCN}} / \partial N_{\mathrm{CN}}\left(S, D_{\mathrm{d}}\right)$ into a corresponding value of $H\left(\kappa_{\mathrm{c}}, D_{\mathrm{d}}\right)$. Fig. 5 shows a plot of $H\left(\kappa, D_{\mathrm{d}}\right)$ vs. $\kappa$ that corresponds to the plot of $\partial N_{\mathrm{CCN}} / \partial N_{\mathrm{CN}}\left(S, D_{\mathrm{d}}\right)$ vs. $D_{\mathrm{d}}$ in Fig. 3. For each of the non-size-dependent hygroscopicity distributions assumed in Case A and B, the CCN efficiency spectra observed at different supersaturations converge into a single curve of $H\left(\kappa, D_{\mathrm{d}}\right)$ vs. $\kappa$ : a step function for the perfectly mixed aerosol (Case A) and monomodal lognormal CDF for the imperfectly internally mixed aerosol (Case B). The same applies to the non-size-dependent low hygroscopicity mode in Case $\mathrm{C}$ (mode 2 with $\bar{\kappa}_{\mathrm{g}, 2}=0.05$ ). For the size-dependent mode 1, however, we obtain different curves at different supersaturations (red dotted, dashed, and solid lines around $\kappa \sim 0.3$ ). The different midpoint values
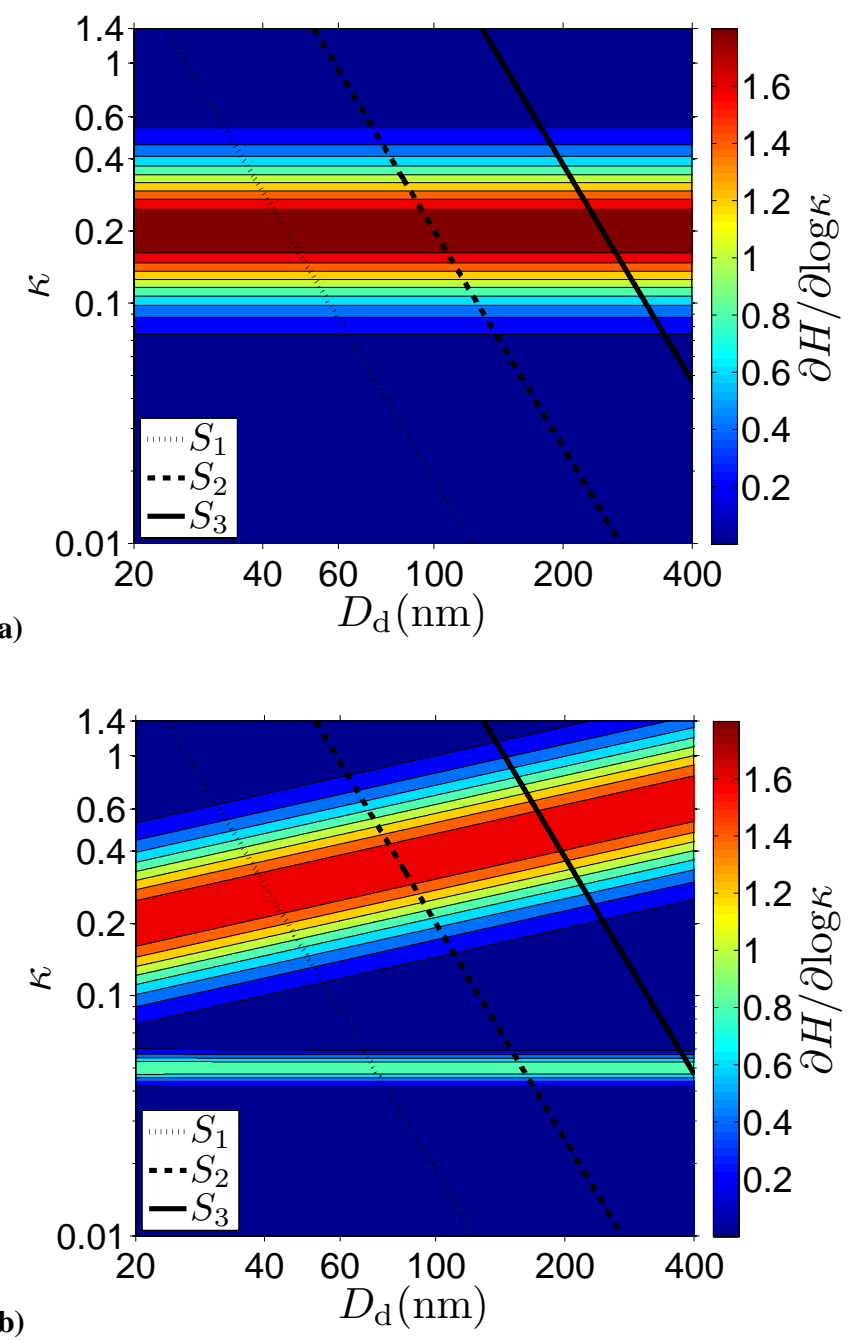

Fig. 4. Logarithmic probability distributions of particle hygroscopicity, $h_{10}\left(\kappa, D_{\mathrm{d}}\right)=\partial H\left(\kappa, D_{\mathrm{d}}\right) / \partial \log \kappa$, plotted over effective hygroscopicity parameter $(\kappa)$ and dry particle diameter $\left(D_{\mathrm{d}}\right)$ for model aerosols of Case B (a) and of Case C (b). The tilted black lines indicate $D_{\mathrm{d}}$ scans at fixed supersaturations $\left(S_{1}=0.86 \%, S_{2}=0.26 \%\right.$, $S_{3}=0.067 \%$ ).

of the CDF curves of mode $1(\kappa \sim 0.25-0.45)$, correspond to the different intersections of the " $D_{\mathrm{d}}$ scan" at constant $S$ (black tilted lines) with the maximum of the PDF of $\kappa$ in Fig. $4 b$ (center of red bar).

As outlined above, methods I and II are different ways of probing $H\left(\kappa, D_{\mathrm{d}}\right)$. If $H\left(\kappa, D_{\mathrm{d}}\right)$ is not size-dependent, distribution plots of $H\left(\kappa, D_{\mathrm{d}}\right)$ vs. $\kappa$ obtained by " $S$ scan" at constant $D_{\mathrm{d}}\left(\operatorname{method}\right.$ I) or by " $D_{\mathrm{d}}$ scan" at constant $S$ (method II) are the same. If, however, $H\left(\kappa, D_{\mathrm{d}}\right)$ is size-dependent, differences are expected. For Case $\mathrm{C}$, we compare the $\mathrm{CDF}$ curves of $H\left(\kappa, D_{\mathrm{d}}\right)$ vs. $\kappa$ obtained by method II at $S_{1}-S_{3}$ (red lines in Figs. 5 and 6a) with the CDF curves of $H\left(\kappa, D_{\mathrm{d}}\right)$ vs. $\kappa$ obtained by method I at $D_{\mathrm{d}, 1}-D_{\mathrm{d}, 3}$ (black lines in Fig. 6a). The 


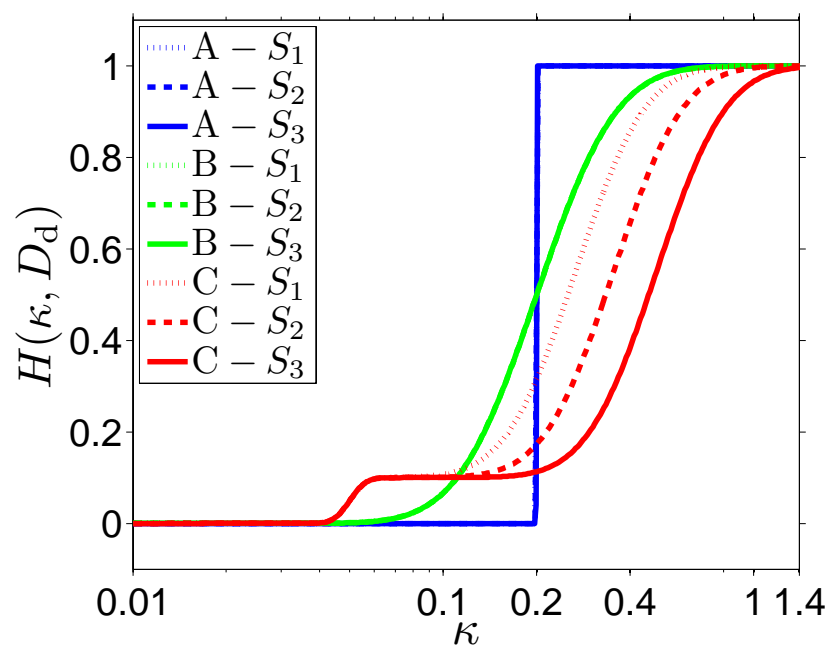

Fig. 5. Cumulative particle hygroscopicity distributions, $H\left(\kappa, D_{\mathrm{d}}\right)$, calculated from the $\mathrm{CCN}$ efficiency spectra of hypothetical case study aerosols (Fig. 3). Each line represents the cumulative distribution of one type of model aerosol (Case A, B, or C, as specified in Table 1 and Fig. 4$)$ at a fixed supersaturation $S\left(S_{1}=0.86 \%\right.$, $S_{2}=0.26 \%, S_{3}=0.067 \%$ ). The three blue (or green) lines at different $S$ converge into a single curve.

three diameter values $D_{\mathrm{d}, 1}-D_{\mathrm{d}, 3}$ were calculated by solving Eq. (23) with $\kappa=\bar{\kappa}_{\mathrm{g}, 1}\left(D_{\mathrm{d}}\right)=0.2\left(D_{\mathrm{d}} / 20 \mathrm{~nm}\right)^{0.4}$ for the supersaturation values $S_{1}-S_{3}$. They correspond to the intersections of the " $D_{\mathrm{d}}$ scan" at constant $S$ (black tilted lines) with the maximum of the PDF of $\kappa$ for mode 1 in Fig. $4 \mathrm{~b}$ (center of red bar).

The results of method I are exactly the same for the nonsize-dependent low hygroscopicity mode (mode 2), but for the size-dependent mode 1 they are slightly different from method II. While the modal values of $\kappa$ remain the same, method I yields a wider spread of $H\left(\kappa, D_{\mathrm{d}}\right)$ vs. $\kappa$. Accordingly, the corresponding peak in the logarithmic PDFs shown in Fig. $6 \mathrm{~b}$ are a little wider and lower for method I (partial derivative, $\left.\partial H\left(\kappa, D_{\mathrm{d}}\right) / \partial \log \kappa\right)$ than for method II (total derivative, $\left.d H\left(\kappa, D_{\mathrm{d}}\right) / d \log \kappa\right)$. Considering other potential uncertainties related to measurement techniques and conditions, however, the mathematical deviations between partial and total derivative appear relatively minor (Sect. 2.4).

Of course the differences between methods I and II depend on the form of the probed hygroscopicity distribution. For example, the spread of the distribution obtained with method I would be smaller than that of method II if the hygroscopicity increased with size, and the differences would be larger if the size-dependence were stronger. Thus, the results of the above sensitivity study for a specific model scenario should not be over-generalized. Considering, however, that the size-dependencies observed in recent field studies seem to be comparable and not much larger than assumed in the model scenario, we suggest that for atmospheric aerosols

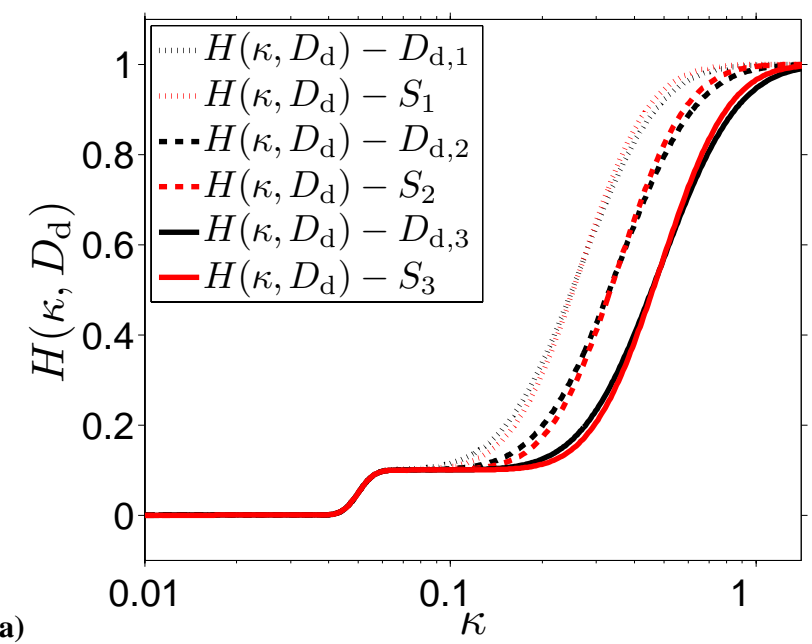

(a)

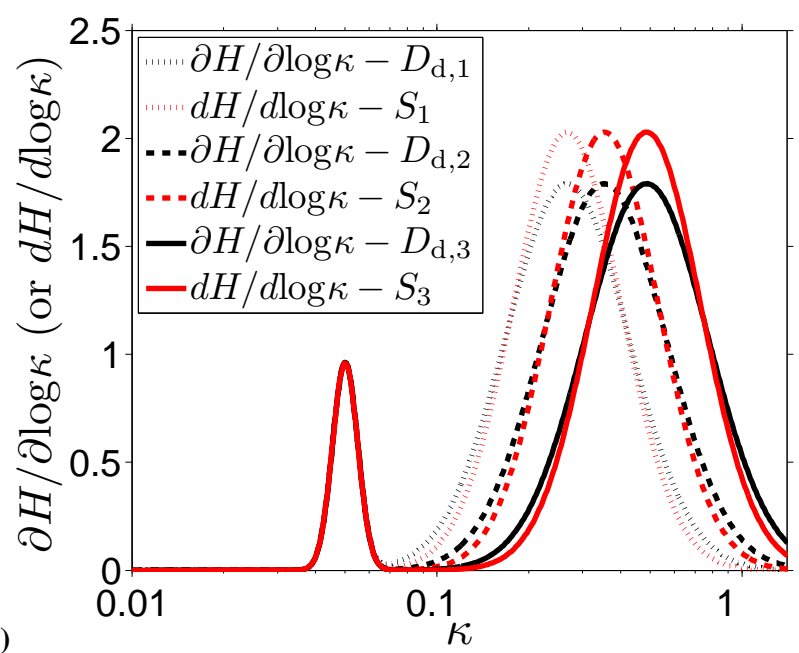

Fig. 6. Cumulative particle hygroscopicity distributions, $H\left(\kappa, D_{\mathrm{d}}\right)$ (a), and corresponding logarithmic probability distributions, $\partial H\left(\kappa, D_{\mathrm{d}}\right) / \partial \log \kappa$ or $d H\left(\kappa, D_{\mathrm{d}}\right) / d \log \kappa(\mathbf{b})$, for the model aerosol of Case C obtained by method I (" $S$ scan" at $D_{\mathrm{d}, 1}, D_{\mathrm{d}, 2}$ or $D_{\mathrm{d}, 3}$ ) and method II (" $D_{\mathrm{d}}$ scan" at $S_{1}=0.86 \%, S_{2}=0.26 \%$ or $S_{3}=0.067 \%$ ).

the logarithmic hygroscopicity PDFs obtained with method II $\left(d H\left(\kappa, D_{\mathrm{d}}\right) / d \log \kappa\right)$ may be well suited to approximate the ones obtained with method $\mathrm{I}\left(h_{10}=\partial H\left(\kappa, D_{\mathrm{d}}\right) / \partial \log \kappa\right)$.

\subsection{Measured CCN efficiency spectra and lognormal fitting}

To test and illustrate the practical applicability of the $\kappa$ distribution concept, we applied it to size-resolved $\mathrm{CCN}$ measurement data of polluted megacity air from the CAREBeijing2006 campaign in Beijing, China. The CCN measurements were performed at the Yufa site in the southern outskirts of Beijing, roughly $50 \mathrm{~km}$ away from the urban center in Beijing $\left(39.51^{\circ} \mathrm{N}, 116.31^{\circ} \mathrm{E}\right)$ over the period of 10 August to 


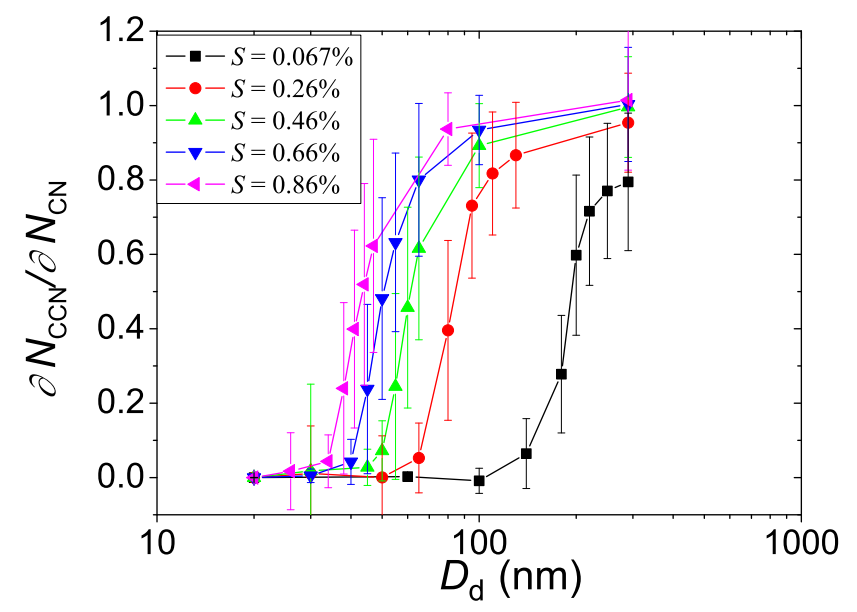

Fig. 7. Average CCN efficiency spectra for the CAREBeijing-2006 campaign (10 August to 8 September 2006, Yufa, Beijing, China). The data points and error bars represent arithmetic mean values \pm one standard deviation. Note that the experimental uncertainties $(<$ $10 \%$, Rose et al., 2010a) were smaller than the temporal variability of the measurement data as indicated by the error bars.

8 September 2006. Details about the measurement location and conditions are reported by Garland et al. (2009) and Wiedensohler et al. (2009). The size-resolved CCN measurements were performed following method II (" $D_{\mathrm{d}}$ scan" at constant $S$ ), and the data were recorded and processed as detailed by Rose et al. (2010a), except that the DMA transfer function correction was not applied, because it is based on the assumption of perfect internal mixing (Sect. 2.3.1.3 in Rose et al., 2008).

Figure 7 shows the campaign average and variability of $\mathrm{CCN}$ efficiency spectra observed at the five investigated supersaturation levels ( $S=0.067 \%$ to $0.86 \%$ ), and Fig. 8a shows the corresponding cumulative hygroscopicity distributions, $H\left(\kappa, D_{\mathrm{d}}\right)$, obtained through Eqs. (21) and (22).

Comparison of the measurement-derived CDFs of $H\left(\kappa, D_{\mathrm{d}}\right)$ in Fig. 8a with the model scenarios in Fig. 5 suggests a size-dependent, imperfectly internally mixed mode around $\kappa \sim 0.4$, similar to mode 1 in Case $\mathrm{C}$.

The data also indicate a small but significant fraction of particles with very low hygroscopicity $(\approx 10 \%, \kappa<0.1)$. These are most likely externally mixed soot particles freshly emitted from strong local and regional sources (Cheng et al., 2009; Garland et al., 2009; Wehner et al., 2009; Rose et al., 2010a). They may be regarded as a low hygroscopicity mode analogous to mode 2 in Case C, but the dispersion of $\kappa$ values appears to be much wider. The range and resolution of measurement data was not sufficient to cover and resolve this low hygroscopicity mode.

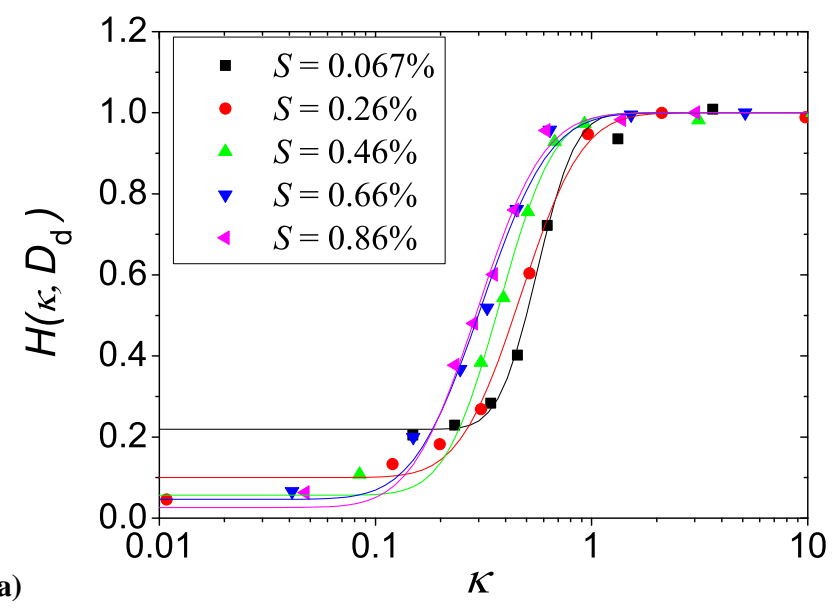

(a)

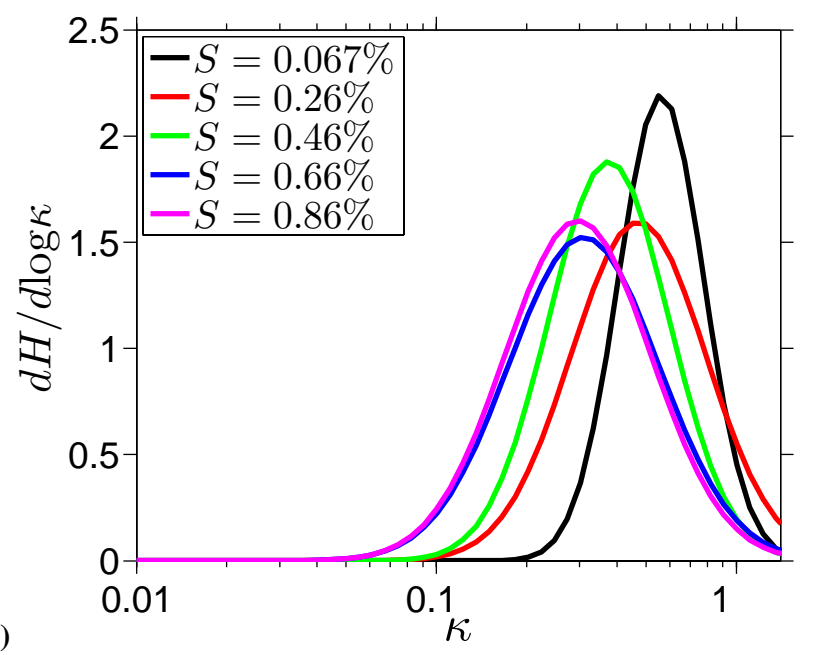

Fig. 8. Average cumulative particle hygroscopicity distributions, $H\left(\kappa, D_{\mathrm{d}}\right)($ a) corresponding to the CCN efficiency spectra (Fig. 7) observed in the CAREBeijing-2006 campaign. The color lines in (a) are the fitted curves in the form of Eq. (34) to the corresponding measurement data points (of the same color). The logarithmic probability distributions, $d H\left(\kappa, D_{\mathrm{d}}\right) / d \log \kappa$ in (b) were calculated from the fitted curves shown in (a).

For size-resolved CCN measurements, the lower limit $\kappa_{\mathrm{ml}}$ of the hygroscopicity parameter range covered by each scan is determined by the corresponding upper limit values of water vapor supersaturation $S_{\max }$ (method I) or dry particle diameter, $D_{\mathrm{d}, \max }\left(\right.$ method II): $\kappa_{\mathrm{ml}}=\kappa_{\mathrm{c}}\left(S_{\max }, D_{\mathrm{d}}\right)(\operatorname{method} \mathrm{I})$ or $\kappa_{\mathrm{ml}}=\kappa_{\mathrm{c}}\left(S, D_{\mathrm{d}, \max }\right)\left(\right.$ method II). If all particles with $\kappa>\kappa_{\mathrm{ml}}$ are assumed belonging to a single-mode lognormal hygroscopicity distribution function (imperfect internal mixture), the following modified version of Eq. (16) can be used to fit measurement-derived data of $H\left(\kappa, D_{\mathrm{d}}\right)$ : 
Table 2. Lognormal hygroscopicity distribution fit parameters for the CAREBeijing-2006 field campaign data (Eq. 34 and Fig. 8). The goodness of the least-squares fit is indicated by the coefficient of determination $\left(R^{2}\right)$ and the root mean square error (RMSE); $\kappa_{\mathrm{ml}}$ is the lower limit of the hygroscopicity parameter range covered by measurement data.

\begin{tabular}{lcccccc}
\hline & $a$ & $\overline{\kappa_{\mathrm{g}}}$ & $\sigma_{\kappa, \mathrm{g}}$ & $R^{2}$ & $\mathrm{RMSE}$ & $\kappa_{\mathrm{ml}}$ \\
\hline$S=0.067 \%$ & 0.78 & 0.56 & 1.38 & 0.995 & 0.028 & 0.149 \\
$S=0.26 \%$ & 0.90 & 0.47 & 1.67 & 0.995 & 0.033 & 0.011 \\
$S=0.46 \%$ & 0.94 & 0.38 & 1.60 & 0.994 & 0.034 & 0.003 \\
$S=0.66 \%$ & 0.95 & 0.31 & 1.77 & 0.992 & 0.043 & 0.002 \\
$S=0.86 \%$ & 0.97 & 0.30 & 1.74 & 0.994 & 0.034 & 0.001 \\
\hline
\end{tabular}

Table 3. Acronyms

\begin{tabular}{ll}
\hline Symbol & Description \\
\hline CCN & Cloud condensation nuclei \\
CDF & Cumulative distribution function \\
CN & Condensation nuclei \\
CPC & Condensation particle counter \\
DMA & Differential mobility analyzer \\
HTDMA & Hygroscopicity tandem differential mobility analyzer \\
PDF & Probability distribution function \\
RMSE & Root mean square error \\
SP2 & Single-particle soot photometer \\
SPMS & Single particle mass spectrometers \\
STEM & Scanning and transmission electron microscopes \\
VTDMA & Volatility tandem differential mobility analyzer \\
\hline
\end{tabular}

$$
\begin{aligned}
H\left(\kappa, D_{\mathrm{d}}\right) & =(1-a)+a\left(\frac{1}{2}+\frac{1}{2} \operatorname{erf}\left(\frac{\log \kappa-\log \bar{\kappa}_{\mathrm{g}}}{\sqrt{2} \log \sigma_{\kappa, g}}\right)\right) \\
& =1-\frac{a}{2}+\frac{a}{2} \operatorname{erf}\left(\frac{\log \kappa-\log \bar{\kappa}_{\mathrm{g}}}{\sqrt{2} \log \sigma_{\kappa, g}}\right)
\end{aligned}
$$

Here $a$ is the number fraction of particles in the fit single mode, $\bar{\kappa}_{\mathrm{g}}$ is the geometric mean $\kappa$ of the fit mode and $\sigma_{\kappa, \mathrm{g}}$ is the geometric standard deviation of $\kappa$ for the fit mode.

The best fit parameters of Eq. (34) to the average aerosol hygroscopicity distributions are listed in Table 2 and plotted in Fig. 8a. During the CAREBeijing-2006 campaign, over $95 \%$ of the $\sim 1536$ individual distributions $H\left(\kappa, D_{\mathrm{d}}\right)$ recorded could be fitted with $R^{2}>0.8$ by Eq. (34). Similarly good fitting results were obtained with size-resolved $\mathrm{CCN}$ measurement data from other recent field campaigns investigating polluted megacity air (PRD2006, Rose et al., 2010a) as well as pristine rainforest air (AMAZE-08, Gunthe et al., 2009). Thus, Eq. (34) appears suitable for an approximate description of atmospheric aerosol hygroscopicity distributions. Nevertheless, other fit functions such as normal or Gamma distributions, power laws, etc. (Deirmendjian, 1969;

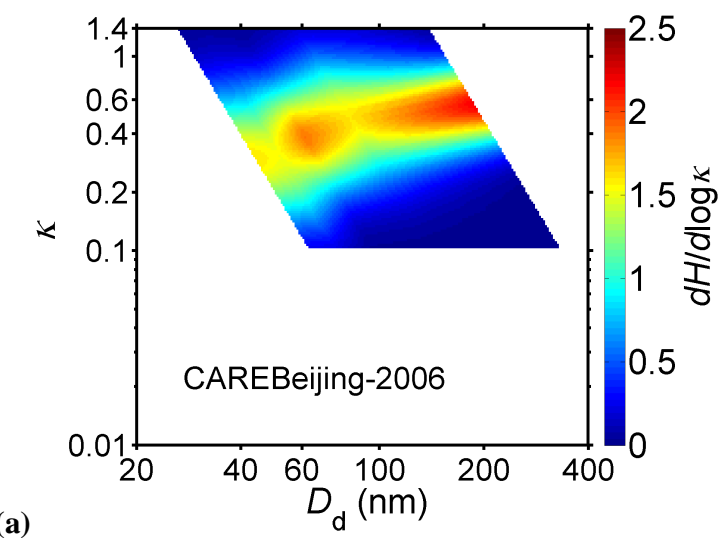

(a)

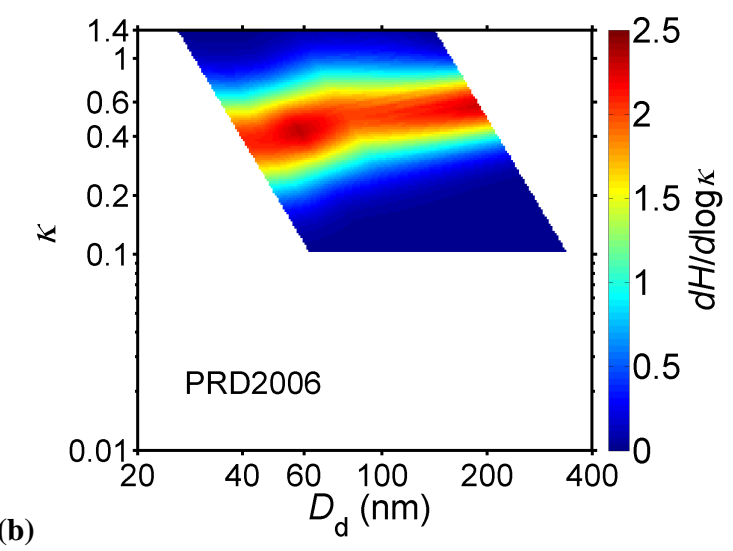

(b)

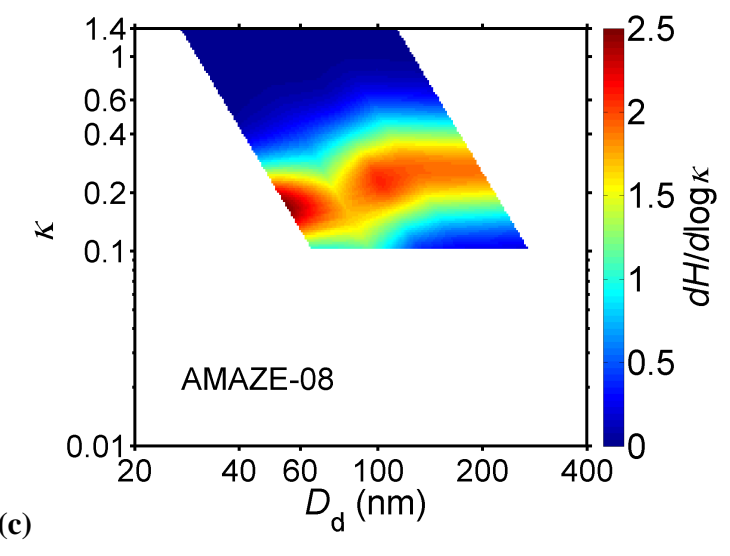

Fig. 9. Average logarithmic probability distributions of particle hygroscopicity, $d H\left(\kappa, D_{\mathrm{d}}\right) / d \log \kappa$, plotted over effective hygroscopicity parameter $(\kappa)$ and dry particle diameter $\left(D_{\mathrm{d}}\right)$ for CAREBeijing2006 (a), PRD2006 (b) and AMAZE-08 (c). The $d H\left(\kappa, D_{\mathrm{d}}\right) / d \log \kappa$ curves from the Fig. $8 \mathrm{~b}$ were interpolated over the $D_{\mathrm{d}}-\kappa$ plane by using a 2-D triangle-based linear interpolation method.

Pruppacher and Klett, 1997; Seinfeld and Pandis, 2006) or multiple lognormal modes may be equally or better suited depending on aerosol composition and the range and resolution of measurement data, which should be explored in futures studies.

Differentiating $H\left(\kappa, D_{\mathrm{d}}\right)$ (the CDFs) by $\log \kappa$ yields the corresponding PDFs $d H\left(\kappa, D_{\mathrm{d}}\right) / d \log \kappa$ as shown in Fig. 8a 
Table 4. Symbols

\begin{tabular}{|c|c|c|}
\hline Symbol & Unit & Quantity \\
\hline$a_{i}\left(D_{\mathrm{d}}\right)$ & & Number fraction of the $i$ th fit mode in a lognormal distribution fit to $H\left(\kappa, D_{\mathrm{d}}\right)$ at $D_{\mathrm{d}}$ \\
\hline$D_{\mathrm{d}}$ & m (unless specified) & Dry particle diameter \\
\hline$D_{\mathrm{d}, \mathrm{c}}$ & m (unless specified) & Critical dry particle diameter \\
\hline$D_{\mathrm{W}}$ & m (unless specified) & Wet particle diameter \\
\hline$F\left(D_{\mathrm{w}}, D_{\mathrm{d}}, s\right)$ & & Number fraction of particles of dry size $D_{\mathrm{d}}$ with equilibrated wet diameter smaller than $D_{\mathrm{w}}$ at $s$ \\
\hline$H\left(\kappa, D_{\mathrm{d}}\right)$ & & Cumulative particle hygroscopicity distribution function \\
\hline$h\left(\kappa, D_{\mathrm{d}}\right)$ & & Particle hygroscopicity (probability) distribution function with respect to $\kappa$ \\
\hline$h_{e}\left(\kappa, D_{\mathrm{d}}\right)$ & & Particle hygroscopicity (probability) distribution function with respect to $\ln \kappa$ \\
\hline$h_{10}\left(\kappa, D_{\mathrm{d}}\right)$ & & Particle hygroscopicity (probability) distribution function with respect to $\log \kappa$ \\
\hline$M_{\mathrm{W}}$ & $\mathrm{kg} \mathrm{mol}^{-1}$ & Molar mass of water \\
\hline$N\left(D_{\mathrm{d}}\right)$ & $\mathrm{cm}^{-3}$ & Cumulative particle size distribution function \\
\hline$N_{\mathrm{CCN}}\left(S, D_{\mathrm{d}}\right)$ & $\mathrm{cm}^{-3}$ & $\mathrm{CCN}$ (at $S$ ) number concentration of particles smaller than $D_{\mathrm{d}}$ \\
\hline$N_{\mathrm{CN}}\left(D_{\mathrm{d}}\right)$ & $\mathrm{cm}^{-3}$ & $\mathrm{CN}$ number concentration of particles smaller than $D_{\mathrm{d}}$ \\
\hline$n\left(D_{\mathrm{d}}\right)$ & $\mathrm{m}^{-1} \mathrm{~cm}^{-3}$ & Particle size distribution function with respect to $D_{\mathrm{d}}$ \\
\hline$R$ & $\mathrm{~J} \mathrm{~K}^{-1} \mathrm{~mol}^{-1}$ & Universal gas constant \\
\hline RH & $\%$ & Relative humidity \\
\hline$T$ & $\mathrm{~K}$ & Temperature \\
\hline$S$ & $\%$ & Water vapor supersaturation \\
\hline$S_{\mathrm{c}}$ & $\%$ & Critical water vapor supersaturation \\
\hline$s$ & & Water vapor saturation ratio \\
\hline$s_{\mathrm{c}}$ & & Critical water vapor saturation ratio \\
\hline$\kappa$ & & Effective hygroscopicity parameter \\
\hline$\kappa_{\mathrm{c}}$ & & Critical effective hygroscopicity parameter \\
\hline$\kappa_{\mathrm{ml}}$ & & Lower measurement limit for the size resolved CCN measurements \\
\hline$\kappa_{\text {med }}\left(D_{\mathrm{d}}\right)$ & & Median $\kappa$ for particles of size $D_{\mathrm{d}}$ \\
\hline$\kappa_{\text {mode }}\left(D_{\mathrm{d}}\right)$ & & Local maximum of the $h\left(\kappa, D_{\mathrm{d}}\right)$ distribution for particles of size $D_{\mathrm{d}}$ \\
\hline $\bar{\kappa}\left(D_{\mathrm{d}}\right)$ & & Arithmetic mean $\kappa$ for particles of size $D_{\mathrm{d}}$ \\
\hline $\bar{\kappa}_{\mathrm{g}}\left(D_{\mathrm{d}}\right)$ & & Geometric mean $\kappa$ for particles of size $D_{\mathrm{d}}$ \\
\hline $\bar{\kappa}_{\mathrm{g}, i}\left(D_{\mathrm{d}}\right)$ & & Geometric mean $\kappa$ of the $i$ th fit mode in a lognormal distribution fit to $H\left(\kappa, D_{\mathrm{d}}\right)$ at $D_{\mathrm{d}}$ \\
\hline$\rho_{\mathrm{W}}$ & $\mathrm{kg} \mathrm{m}^{-3}$ & Density of pure water \\
\hline$\sigma_{\mathrm{sol}}$ & $\mathrm{J} \mathrm{m}^{-2}$ & Surface tension of solution droplet \\
\hline$\sigma_{\mathrm{w}}$ & $\mathrm{J} \mathrm{m}^{-2}$ & Surface tension of pure water \\
\hline$\sigma_{\kappa}\left(D_{\mathrm{d}}\right)$ & & Standard deviation of $\kappa$ for particles of size $D_{\mathrm{d}}$ \\
\hline$\sigma_{\kappa, \mathrm{g}}\left(D_{\mathrm{d}}\right)$ & & Geometric standard deviation of $\kappa$ for particles of size $D_{\mathrm{d}}$ \\
\hline$\sigma_{\kappa, \mathrm{g}, i}\left(D_{\mathrm{d}}\right)$ & & Geometric standard deviation of $\kappa$ of the $i$ th fit mode in a lognormal distribution fit to $H\left(\kappa, D_{\mathrm{d}}\right)$ at $D_{\mathrm{d}}$ \\
\hline
\end{tabular}

and $8 b$. Interpolation between the PDFs observed at different supersaturations yields an approximate representation of the distribution of the particle mode with $\kappa \geq \kappa_{\mathrm{ml}}$ in the $D_{\mathrm{d}}-\kappa$ plane as shown in Fig. 9a. Similar to the more hygroscopic mode 1 in the model scenario Case C (Fig. 4b), the modal $\kappa$ value tends to increase with $D_{\mathrm{d}}$.

Besides the CAREBeijing-2006 campaign, the same approach was also successfully applied to other data sets. For example, Fig. 9b shows a similar PDF of particle hygroscopicity obtained from size-resolved $\mathrm{CCN}$ measurements in polluted megacity air and biomass burning smoke near Guangzhou, China (PRD2006 campaign, 1-30 July 2006; Rose et al., 2010a); and Fig. 9c illustrates a PDF of particle hygroscopicity for pristine rainforest air measured in Brazil (AMAZE-08, 14 Feburary-12 March 2008; Gunthe et al., 2009).
As outlined above, when we applied modified single-mode lognormal distribution function (Eq. 34) for the fitting of the size-resolved CCN field measurement data sets, the distribution information with $\kappa<0.1$ can not be retrieved because of the low $\kappa$ resolution or the detection limit $\kappa_{\mathrm{ml}}$. Thus, the interpolated PDFs shown in Fig. 9a provide no information about the low hygroscopicity particle mode. To avoid any misinterpretation, we limit the contour plot area to $\kappa \geq 0.1$.

Size-resolved CCN measurements with a higher range and resolution of $S$ and $D_{\mathrm{d}}$ would be required to resolve the externally mixed low hygroscopicity mode. Alternatively or in addition, such information could be obtained from HTDMA measurement data, which were not available for the CCN data sets presented in Fig. 9. For a comprehensive characterization of aerosol particle hygroscopicity distributions in future studies we recommend a combination of size-resolved $\mathrm{CCN}$ measurements with a large range and high resolution 
of $S$ and $D_{\mathrm{d}}$ (e.g. Moore et al., 2009, 2010) in combination with HTDMA measurements and detailed measurements of aerosol composition including refractory components (STEM, SPMS, VTDMA, etc.; for acronyms and symbols, refer to Tables 3 and 4).

\section{Conclusions}

In this study, a general concept of aerosol particle hygroscopicity distribution was introduced and related to HTDMA and size-resolved CCN measurements. Model aerosols were used to illustrate the concept, and its practical applicability was demonstrated with exemplary HTDMA and CCN field measurement data. The main conclusions are as follows:

(1) Cumulative hygroscopicity distribution functions (CDF), $H\left(\kappa, D_{\mathrm{d}}\right)$, can be derived from HTDMA and size-resolved $\mathrm{CCN}$ measurements. With the help of single particle analysis techniques, it should also be possible to predict $H\left(\kappa, D_{\mathrm{d}}\right)$ from chemical composition data.

(2) Differentiation of $H\left(\kappa, D_{\mathrm{d}}\right)$ by $d \log \kappa$ yields the corresponding logarithmic probability distribution function (PDF). Depending on the technique applied for size-resolved CCN measurements (" $S$ scan" or " $D_{\mathrm{d}}$ scan"), the PDF corresponds to a partial derivative $\left(\partial H\left(\kappa, D_{\mathrm{d}}\right) / \partial \log \kappa\right)$ or to a total derivative $\left(d H\left(\kappa, D_{\mathrm{d}}\right) / d \log \kappa\right)$. The partial derivative obtained from an " $S$ scan" represents the hygroscopicity distribution at a fixed particle size and is easier to interpret and compare directly with size-resolved data of aerosol composition than the total derivative obtained from a " $D_{\mathrm{d}}$ scan". If $H\left(\kappa, D_{\mathrm{d}}\right)$ exhibits no strong size dependence, which appears likely for most atmospheric conditions, the partial derivative can be approximated by the total derivative.

(3) Lognormal distribution functions were found to be suitable for approximately describing the hygroscopicity distribution of aerosols in polluted megacity air as well as in pristine rainforest air as determined by sizeresolved $\mathrm{CCN}$ measurements.

(4) For detailed characterization of aerosol hygroscopicity distributions, including externally mixed particles of low hygroscopicity such as freshly emitted soot, we suggest that size-resolved $\mathrm{CCN}$ measurements with a wide range and high resolution of water vapor supersaturation and dry particle diameter should be combined with comprehensive HTDMA measurements and sizeresolved or single-particle measurements of aerosol chemical composition, including refractory components.
(5) In field and laboratory experiments, hygroscopicity distribution data from HTDMA and CCN measurements can complement mixing state information from optical, chemical and volatility-based techniques (SP2, STEM, SPMS, VTDMA, etc.). Moreover, we propose and intend to use hygroscopicity distribution functions in model studies investigating the influence of aerosol mixing state on the formation of cloud droplets.

Acknowledgements. This work was funded by the Max Planck Society (MPG) and the European integrated project on aerosol cloud climate and air quality interactions (No 036833-2, EUCAARI). The authors gratefully acknowledge support by the CAREBeijing-2006 group. The authors would also like to thank T. W. Andreae and D. Pickersgill for their help in text editing. We thank M. Gysel, J. Rissler and an anonymous referee for stimulating comments and suggestions.

The service charges for this open access publication have been covered by the Max Planck Society.

Edited by: E. Swietlicki

\section{References}

Aitchison, J. and Brown, J. A. C.: The lognormal distribution function, Cambridge Univ. Press, Cambridge, UK, 1957.

Andreae, M. O. and Rosenfeld, D.: Aerosol-cloud-precipitation interactions. Part 1. The nature and sources of cloud-active aerosols, Earth-Sci. Rev., 89, 13-41, 2008.

Buzorius, G., Zelenyuk, A., Brechtel, F., and Imre, D.: Simultaneous determination of individual ambient particle size, hygroscopicity and composition, Geophys. Res. Lett., 29(20), 1974, doi:10.1029/2001g1014221, 2002.

Cheng, Y. F., Berghof, M., Garland, R. M., Wiedensohler, A., Wehner, B., Müller, T., Su, H., Zhang, Y. H., Achtert, P., Nowak, A., Pöschl, U., Zhu, T., Hu, M., and Zeng, L. M.: Influence of soot mixing state on aerosol light absorption and single scattering albedo during air mass aging at a polluted regional site in northeastern china, J. Geophys. Res., 114, D00G10, doi:10.1029/2008jd010883, 2009.

Clegg, S. L., Kleeman, M. J., Griffin, R. J., and Seinfeld, J. H.: Effects of uncertainties in the thermodynamic properties of aerosol components in an air quality model - Part 1: Treatment of inorganic electrolytes and organic compounds in the condensed phase, Atmos. Chem. Phys., 8, 1057-1085, doi:10.5194/acp-81057-2008, 2008.

Deirmendjian, D.: Electromagnetic scattering on spherical polydisersions, Elsevier, New York, 1967.

Dusek, U., Frank, G. P., Hildebrandt, L., Curtius, J., Schneider, J., Walter, S., Chand, D., Drewnick, F., Hings, S., Jung, D., Borrmann, S., and Andreae, M. O.: Size matters more than chemistry for cloud-nucleating ability of aerosol particles, Science, 312, 1375-1378, doi:10.1126/science.1125261, 2006.

Frank, G. P., Dusek, U., and Andreae, M. O.: Technical note: A method for measuring size-resolved $\mathrm{CCN}$ in the atmosphere, Atmos. Chem. Phys. Discuss., 6, 4879-4895, doi:10.5194/acpd-64879-2006, 2006. 
Garland, R. M., Yang, H., Schmid, O., Rose, D., Nowak, A., Achtert, P., Wiedensohler, A., Takegawa, N., Kita, K., Miyazaki, Y., Kondo, Y., Hu, M., Shao, M., Zeng, L. M., Zhang, Y. H., Andreae, M. O., and Pöschl, U.: Aerosol optical properties in a rural environment near the mega-city Guangzhou, China: implications for regional air pollution, radiative forcing and remote sensing, Atmos. Chem. Phys., 8, 5161-5186, doi:10.5194/acp-85161-2008, 2008.

Garland, R. M., Schmid, O., Nowak, A., Achtert, P., Wiedensohler, A., Gunthe, S. S., Takegawa, N., Kita, K., Kondo, Y., Hu, M., Shao, M., Zeng, L. M., Zhu, T., Andreae, M. O., and Pöschl, U.: Aerosol optical properties observed during campaign of air quality research in Beijing 2006 (CAREbeijing2006): characteristic differences between the inflow and outflow of Beijing city air, J. Geophys. Res., 114, D00G04, doi:10.1029/2008jd010780, 2009.

Gunthe, S. S., King, S. M., Rose, D., Chen, Q., Roldin, P., Farmer, D. K., Jimenez, J. L., Artaxo, P., Andreae, M. O., Martin, S. T., and Pöschl, U.: Cloud condensation nuclei in pristine tropical rainforest air of Amazonia: size-resolved measurements and modeling of atmospheric aerosol composition and CCN activity, Atmos. Chem. Phys., 9, 7551-7575, doi:10.5194/acp-9-75512009, 2009.

Kammermann, L., Gysel, M., Weingartner, E., Herich, H., Cziczo, D. J., Holst, T., Svenningsson, B., Arneth, A., and Baltensperger, U.: Subarctic atmospheric aerosol composition: 3. Measured and modeled properties of cloud condensation nuclei, J. Geophys. Res., 115, D04202, doi:10.1029/2009JD012447, 2010.

Kreidenweis, S. M., Petters, M. D., and Chuang, P. Y.: Cloud particle precursors, in: Clouds in the perturbed climate system - their relationship to energy balance, atmospheric dynamics, and precipitation, edited by: Heintzenberg, J. and Charlson, R. J., MIT Press, Cambridge, 291-317, 2009.

Krejci, R., Ström, J., de Reus, M., and Sahle, W.: Single particle analysis of the accumulation mode aerosol over the northeast Amazonian tropical rain forest, Surinam, South America, Atmos. Chem. Phys., 5, 3331-3344, doi:10.5194/acp-5-3331-2005, 2005.

Kuwata, M. and Kondo, Y.: Dependence of size-resolved $\mathrm{CCN}$ spectra on the mixing state of nonvolatile cores observed in Tokyo, J. Geophys. Res., 113, D19202, doi:10.1029/2007JD009761, 2008.

Köhler, H.: The nucleus in the growth of hygroscopic droplets, T. Faraday Soc., 32, 1152-1161, 1936.

Massling, A., Stock, M., Wehner, B., Wu, Z. J., Hu, M., Brügemann, E., Gnauk, T., Herrmann, H., and Wiedensohler, A.: Size segregated water uptake of the urban submicrometer aerosol in Beijing, Atmos. Environ., 43, 1578-1589, 2009.

McDonald, J. E.: Erroneous cloud-physics applications of raoult law, J. Meteorol., 10, 68-78, 1953.

McMurry, P. H., Litchy, M., Huang, P.-F., Cai, X., Turpin, B. J., Dick, W. D., and Hanson, A.: Elemental composition and morphology of individual particles separated by size and hygroscopicity with the tdma, Atmos. Environ., 30, 101-108, 1996.

Mikhailov, E., Vlasenko, S., Niessner, R., and Pöschl, U.: Interaction of aerosol particles composed of protein and saltswith water vapor: hygroscopic growth and microstructural rearrangement, Atmos. Chem. Phys., 4, 323-350, doi:10.5194/acp-4-323-2004,
2004.

Mikhailov, E., Vlasenko, S., Martin, S. T., Koop, T., and Pöschl, U.: Amorphous and crystalline aerosol particles interacting with water vapor: conceptual framework and experimental evidence for restructuring, phase transitions and kinetic limitations, Atmos. Chem. Phys., 9, 9491-9522, doi:10.5194/acp-9-9491-2009, 2009.

Moore, R. H., and Nenes, A.: Scanning flow CCN analysis - A method for fast measurements of ccn spectra, Aerosol Sci. Technol., 43, 1192-1207, 2009.

Moore, R. H., Nenes, A., and Medina, J.: Scanning Mobility CCN Analysis - A method for fast measurements of size resolved CCN distributions and activation kinetics, Aerosol Sci. Technol., 44 , 861-871, doi:10.1080/02786820903289780, 2010.

Murphy, D. M., Cziczo, D. J., Froyd, K. D., Hudson, P. K., Matthew, B. M., Middlebrook, A. M., Peltier, R. E., Sullivan, A., Thomson, D. S., and Weber, R. J.: Single-particle mass spectrometry of tropospheric aerosol particles, J. Geophys. Res., 111, D23S32, doi:10.1029/2006jd007340, 2006.

Niedermeier, D., Wex, H., Voigtländer, J., Stratmann, F., Brüggemann, E., Kiselev, A., Henk, H., and Heintzenberg, J.: LACIS-measurements and parameterization of sea-salt particle hygroscopic growth and activation, Atmos. Chem. Phys., 8, 579590, doi:10.5194/acp-8-579-2008, 2008.

Orsini, D. A., Wiedensohler, A., and Covert, D. S.: Volatility measurements of atmospheric aerosols in the mid and south pacific using a volatility-tandem-differential-mobility-analyzer, J. Aerosol Sci., 27, S53-S54, 1996.

Petters, M. D. and Kreidenweis, S. M.: A single parameter representation of hygroscopic growth and cloud condensation nucleus activity, Atmos. Chem. Phys., 7, 1961-1971, doi:10.5194/acp-71961-2007, 2007.

Petters, M. D., Carrico, C. M., Kreidenweis, S. M., Prenni, A. J., DeMott, P. J., Collett Jr., J. L., and Moosmüller, H.: Cloud condensation nucleation activity of biomass burning aerosol, J. Geophys. Res., 114, D22205, doi:10.1029/2009jd012353, 2009a.

Petters, M. D., Wex, H., Carrico, C. M., Hallbauer, E., Massling, A., McMeeking, G. R., Poulain, L., Wu, Z., Kreidenweis, S. M., and Stratmann, F.: Towards closing the gap between hygroscopic growth and activation for secondary organic aerosol - Part 2: Theoretical approaches, Atmos. Chem. Phys., 9, 3999-4009, doi:10.5194/acp-9-3999-2009, 2009 b.

Pruppacher, H. R. and Klett, J. D.: Microphysics of clouds and precipitation, Kluwer Academic Publishers, Dordrecht, 1997.

Pöschl, U., Rose, D., and Andreae, M. O.: Climatologies of cloudrelated aerosols - part 2: Particle hygroscopicity and cloud condensation nuclei activity, in: Clouds in the perturbed climate system, edited by: Heintzenberg, J. and Charlson, R. J., MIT Press, Cambridge, 2009.

Reutter, P., Su, H., Trentmann, J., Simmel, M., Rose, D., Gunthe, S. S., Wernli, H., Andreae, M. O., and Pöschl, U.: Aerosoland updraft-limited regimes of cloud droplet formation: influence of particle number, size and hygroscopicity on the activation of cloud condensation nuclei (CCN), Atmos. Chem. Phys., 9, 7067-7080, doi:10.5194/acp-9-7067-2009, 2009.

Rissler, J., Vestin, A., Swietlicki, E., Fisch, G., Zhou, J., Artaxo, P., and Andreae, M. O.: Size distribution and hygroscopic properties of aerosol particles from dry-season biomass burning in Amazonia, Atmos. Chem. Phys., 6, 471-491, doi:10.5194/acp- 
6-471-2006, 2006.

Robinson, R. A. and Stokes, R. H.: Electrolyte solutions, revised, Butterworths Scientific Pub, London, 1959.

Rose, D., Gunthe, S. S., Mikhailov, E., Frank, G. P., Dusek, U., Andreae, M. O., and Pöschl, U.: Calibration and measurement uncertainties of a continuous-flow cloud condensation nuclei counter (DMT-CCNC): CCN activation of ammonium sulfate and sodium chloride aerosol particles in theory and experiment, Atmos. Chem. Phys., 8, 1153-1179, doi:10.5194/acp-8-11532008, 2008.

Rose, D., Nowak, A., Achtert, P., Wiedensohler, A., Hu, M., Shao, M., Zhang, Y., Andreae, M. O., and Pöschl, U.: Cloud condensation nuclei in polluted air and biomass burning smoke near the mega-city Guangzhou, China - Part 1: Size-resolved measurements and implications for the modeling of aerosol particle hygroscopicity and CCN activity, Atmos. Chem. Phys., 10, 33653383, doi:10.5194/acp-10-3365-2010, 2010a.

Rose, D., Garland, R. M., Yang, H., Gunthe, S. S., Su, H., Berghof, M., Cheng, Y. F., Wehner, B., Wiedensohler, A., Takegawa, N., Kondo, Y., Hu, M., Zhang, Y., Andreae, M. O., and Pöchl, U.: Cloud condensation nuclei in polluted air and biomass burning smoke near the mega-city Guangzhou, China - Part 2: Sizeresolved aerosol chemical composition, diurnal cycles, and mixing state of CCN-inactive soot particles, to be submitted, 2010b.

Rose, D.: Measurement and modeling of cloud condensation nuclei in continental air, Doctoral dissertation, Johannes-GutenbergUniversity, Mainz, Germany, 2010c.

Schwarz, J. P., Gao, R. S., Fahey, D. W., Thomson, D. S., Watts, L. A., Wilson, J. C., Reeves, J. M., Darbeheshti, M., Baumgardner, D. G., Kok, G. L., Chung, S. H., Schulz, M., Hendricks, J., Lauer, A., Kärcher, B., Slowik, J. G., Rosenlof, K. H., Thompson, T. L., Langford, A. O., Loewenstein, M., and Aikin, K. C.: Single-particle measurements of midlatitude black carbon and light-scattering aerosols from the boundary layer to the lower stratosphere, J. Geophys. Res., 111, D16207, doi:10.1029/2006jd007076, 2006.

Seinfeld, J. H. and Pandis, S. N.: Atmospheric chemistry and physics, from air pollution to climate change, John Wiley, New York, 362 pp., 2006.

Snider, J., Wex, H., Rose, D., Kristensson, A., Stratmann, F., Hennig, T., Henning, S., Kiselev, A., Bilde, M., Burkhart, M., Dusek, U., Frank, G., Kiendler-Scharr, A., Mentel, Th., Petters, M., and Pöschl, U.: Intercomparison of cloud condensation nuclei and hygroscopic fraction measurements: Coated soot particles investigated during LACIS Experiment in November (LExNo), J. Geophys. Res., doi:10.1029/2009JD012618, in press, 2010.

Stolzenburg, M. and McMurry, P. H.: TDMAFIT user's manual, Tech. Rep. PTL Publication No. 653, University of Minnesota, Department of Mechanical Engineering, Particle Technology Laboratory, 1988.
Sullivan, R. C., Moore, M. J. K., Petters, M. D., Kreidenweis, S. M., Roberts, G. C., and Prather, K. A.: Effect of chemical mixing state on the hygroscopicity and cloud nucleation properties of calcium mineral dust particles, Atmos. Chem. Phys., 9, 33033316, doi:10.5194/acp-9-3303-2009, 2009.

Svenningsson, B., Rissler, J., Swietlicki, E., Mircea, M., Bilde, M., Facchini, M. C., Decesari, S., Fuzzi, S., Zhou, J., Mønster, J., and Rosenørn, T.: Hygroscopic growth and critical supersaturations for mixed aerosol particles of inorganic and organic compounds of atmospheric relevance, Atmos. Chem. Phys., 6, 1937-1952, doi:10.5194/acp-6-1937-2006, 2006.

Svenningsson, B. and Bilde, M.: Relaxed step functions for evaluation of CCN counter data on size-separated aerosol particles, Aerosol Sci., 39, 592-608, 2008.

Swietlicki, E., Hansson, H. C., Meri, K., Svenningsson, B., Massling, A., McFiggans, G., McMurry, P. H., Pet, T., Tunved, P., Gysel, M., Topping, D., Weingartner, E., Baltensperger, U., Rissler, J., Wiedensohler, A., and Kulmala, M.: Hygroscopic properties of submicrometer atmospheric aerosol particles measured with h-tdma instruments in various environments a review, Tellus B, 60, 432-469, 2008.

Vestin, A., Rissler, J., Swietlicki, E., Frank, G. P., and Andreae, M. O.: Cloud-nucleating properties of the amazonian biomass burning aerosol: Cloud condensation nuclei measurements and modeling, J. Geophys. Res., 112, D14201, doi:10.1029/2006jd008104, 2007.

Wehner, B., Berghof, M., Cheng, Y. F., Achtert, P., Birmili, W., Nowak, A., Wiedensohler, A., Garland, R. M., Pöschl, U., $\mathrm{Hu}$, M., and Zhu, T.: Mixing state of nonvolatile aerosol particle fractions and comparison with light absorption in the polluted Beijing region, J. Geophys. Res., 114, D00G17, doi:10.1029/2008jd010923, 2009.

Wex, H., Hennig, T., Salma, I., Ocskay, R., Kiselev, A., Henning, S., Massling, A., Wiedensohler, A., and Stratmann, F.: Hygroscopic growth and measured and modeled critical super-saturations of an atmospheric hulis sample, Geophys. Res. Lett., 34, L02818, doi:10.1029/2006g1028260, 2007.

Wex, H., Petters, M. D., Carrico, C. M., Hallbauer, E., Massling, A., McMeeking, G. R., Poulain, L., Wu, Z., Kreidenweis, S. M., and Stratmann, F.: Towards closing the gap between hygroscopic growth and activation for secondary organic aerosol: Part 1 Evidence from measurements, Atmos. Chem. Phys., 9, 39873997, doi:10.5194/acp-9-3987-2009, 2009.

Wiedensohler, A., Cheng, Y. F., Nowak, A., Wehner, B., Achtert, P., Berghof, M., Birmili, W., Wu, Z. J., Hu, M., Zhu, T., Takegawa, N., Kita, K., Kondo, Y., Lou, S. R., Hofzumahaus, A., Holland, F., Wahner, A., Gunthe, S. S., Rose, D., Su, H., and Pöschl, U.: Rapid aerosol particle growth and increase of cloud condensation nucleus activity by secondary aerosol formation and condensation: A case study for regional air pollution in Northeastern China, J. Geophys. Res., 114, D00G08, doi:10.1029/2008jd010884, 2009. 